\title{
Guidance
}

\section{Guidance Document on Good Cell and Tissue Culture Practice 2.0 (GCCP 2.0)}

\author{
David Pamies1,2, Marcel Leist3,4, Sandra Coecke5, Gerard Bowe5, David G. Allen6, Gerhard Gstraunthaler7, \\ Anna Bal-Price ${ }^{5}$, Francesca Pistollato 5 , Rob B. M. de Vries 8,9 , Helena T. Hogberg 10, Thomas Hartung 3,10 \\ and Glyn Stacey 11,12,13 \\ ${ }^{1}$ Department of Biomedical Science, University of Lausanne, Lausanne, Vaud, Switzerland; ${ }^{2}$ Swiss Centre for Applied Human Toxicology (SCAHT), \\ Basel, Switzerland; ${ }^{3}$ Center for Alternatives to Animal Testing (CAAT) Europe, University of Konstanz, Konstanz, Germany; ${ }^{4}$ In vitro Toxicology and \\ Biomedicine, Dept inaugurated by the Doerenkamp-Zbinden Foundation, University of Konstanz, Konstanz, Germany; ${ }^{5}$ European Commission Joint \\ Research Centre (JRC), Ispra, Italy; ${ }^{6}$ Integrated Laboratory Systems, LLC., Morrisville, NC, USA; ${ }^{7}$ Medical University Innsbruck, Department of \\ Physiology, Innsbruck, Austria; ${ }^{8}$ Evidence-based Toxicology Collaboration, Johns Hopkins Bloomberg School of Public Health, Baltimore, MD, USA; \\ ${ }^{9}$ SYRCLE, Department for Health Evidence, Radboud Institute for Health Sciences, Radboud UMC, Nijmegen, The Netherlands; ${ }^{10}$ Center for Alternatives \\ to Animal Testing (CAAT), Johns Hopkins University, Bloomberg School of Public Health, Baltimore, MD, USA; ${ }^{11}$ International Stem Cell Banking \\ Initiative, Barley, Herts, UK; ${ }^{12}$ National Stem Cell Resource Centre, Institute of Zoology, Chinese Academy of Sciences, Beijing, China; ${ }^{13}$ Innovation \\ Academy for Stem Cell and Regeneration, Chinese Academy of Sciences, Beijing, China
}

\begin{abstract}
Good Cell and Tissue Culture Practice (GCCP) 2.0 is an updated guidance document from GCCP 1.0 (published by ECVAM in 2005), which was developed for practical use in the laboratory to assure the reproducibility of in vitro (cellbased) work. The update in the guidance was essential as cell models have advanced dramatically to more complex culture systems and need more comprehensive quality management to ensure reproducibility and high-quality scientific data. This document describes six main principles to consider when performing cell culture including characterization and maintenance of essential characteristics, quality management, documentation and reporting, safety, education and training, and ethics. The document does not intend to impose detailed procedures but to describe potential quality issues. It is foreseen that the document will require further updates as the science and technologies evolve over time.
\end{abstract}

\section{Contents}

0 Introduction

$0.1 \quad$ Aim and scope of the document

$0.2 \quad$ Background

0.3 The principles of GCCP

0.4 The application of GCCP

1 Principle 1: Understanding your cell culture system and factors that affect it

1.1 Cells and tissues

1.1.1 Isolated organs and tissues

1.1.2 Primary cultures and their passaged derivatives

1.1.3 Cell lines

1.1.4 Cell modification

1.1.5 Complex culture systems

1.2 Cell identity, stability, and sustained functionality

1.2.1 Cell identity

1.2.2 Stability of in vitro culture

Received November 1, 2021

Epub December 9, 2021; @ The Authors, 2022.

ALTEX 39(1), 030-070. doi:10.14573/altex.2111011

Correspondence: Thomas Hartung, MD PhD

Johns Hopkins Bloomberg School of Public Health

Department of Environmental Health \& Engineering

Center for Alternatives to Animal Testing (CAAT)

615 N Wolfe St, Baltimore, MD 21205, USA

(thartun1@jhu.edu)
This is an Open Access article distributed under the terms of the Creative Commons Attribution 4.0 International license (http://creativecommons.org/licenses/by/4.0/) which permits unrestricted use, distribution and reproduction in any medium, provided the original work is appropriately cited. 
1.3 Influence of reagents and environment on cells 8

1.3.1 In vitro culture medium components 8

1.3.2 Physical environmental conditions 9

$1.4 \quad$ Handling and maintenance 10

1.5 Cryopreservation, storage, and shipping 10

1.6 Microbial and viral contaminations 11

2 Principle 2: Management of quality in order to maintain the integrity, validity, and reproducibility of any work conducted

$2.1 \quad$ Quality management 11

$2.2 \quad$ Quality control testing 12

2.2.1 Cells and tissues $\quad 12$

2.2.2 Plastics and glassware 14

2.2.3 Growth media and culture additives 14

2.2.4 Equipment 14

2.2.5 Laboratory environment 15

2.2.6 Data management 15

2.3 GCCP acceptance criteria (GAC) for cell culture status and composition 16

2.3.1 Definition and rationale 16

2.3.2 How to define GCCP acceptance criteria 16

2.3.3 Spatial and structural aspects of cell culture systems 17

2.3.4 Matrix 18

2.3.5 Composite cultures 18

2.3.6 Cellular engineering 18

2.3.7 Effects of analytical instrumentation and methodology on cells 19

2.3.8 Non-mammalian cells and model organisms 19

$3 \quad$ Principle 3: Documentation and reporting of the information necessary to track the materials and methods used, to permit the replication of the work, and to enable the target audience to understand and evaluate the work

3.1 Source, origin, and basic description of cultured cells 20

$3.2 \quad$ Basic culture procedures 20

$\begin{array}{lll}3.2 .1 & \text { Culture conditions } & 20\end{array}$

3.2.2 Subcultivation of cells 21

3.2.3 Cell freezing, banking, and storage 21

$3.3 \quad$ Materials and equipment 21

3.3.1 Culture media and supplements 21

3.3.2 Culture glass, plasticware, and coating substrates 22

3.3.3 Equipment 22

$3.4 \quad$ Record storage and archiving 22

3.4.1 Recording of data 22

3.4.2 Digital data 22

3.5 Documentation 23

Principle 4: Establishment and maintenance of adequate measures to protect individuals and
the environment from any potential hazards

$4.1 \quad$ Risk assessment 24

4.2 Hazards related to cell and tissue culture work 24

4.2.1 Physical hazards 24

4.2.2 Chemical hazards 24

4.2.3 Biological hazards 25

$4.3 \quad$ Risks to the environment 26

4.3.1 Waste disposal 26

4.3.2 Transport 26

$5 \quad$ Principle 5: Compliance with relevant laws and regulations, and with ethical principles 27

$5.1 \quad$ General considerations 27

5.2 Use of human cells and tissues 27

5.3 Use of animal tissues 28 


\section{Introduction}

\subsection{Aim and scope of the document}

This guidance document attempts a current examination of the requirements to assure the reproducibility of in vitro (cell-based) work. Based on a review by a broad range of experts and organizations, this guidance aims to foster a consensus among all concerned on the use of cell and tissue culture systems to establish good cell culture practice, enhance quality of the derived scientific data and associated publications and reports, promote safe and ethical working practices, and facilitate appropriate education and training. These factors are key to promoting reproducibility in scientific research and facilitating the development of novel cell-based technologies, methods, and products for public and commercial purposes.

The scope of the document has deliberately been broadly defined to include systems based on cells and tissues obtained from humans and animals, and issues related to the characterization and maintenance of essential characteristics, as well as quality assurance, recording and reporting, safety, education and training, and ethics. However, many of the principles can be applied to other cells (e.g., plants, fish and insects) though additional considerations might be needed. This revision of the earlier GCCP guidance (Coecke et al., 2005) also explores the specific issues of GCCP for complex culture systems such as pluripotent stem cells (PSCs), “3D”, and microphysiological and organotypic organ-on-a-chip systems (Marx et al., 2016, 2020). However, while GCCP 2.0 aims to address issues for the starting of cell and tissue cultures used in any laboratory work, the process of developing and implementing cell- and tissue-based methods, and the related procedures, are not covered, and for such activities the reader is directed to the guidance document on Good In Vitro Method Practices (GIVIMP) (OECD, 2018).

In this document, we have used the term "tissue" to refer to tissues taken directly from a donor human or animal. In some fields, "tissue" is also used to describe artificial constructs containing different cell types. However, for clarity, multi-cellular, tissue-like systems are described in terms of their precise derivative methods, e.g., 3D culture, co-cultures, organ-on-chip, organotypic cultures, and microphysiological systems. Furthermore, GCCP uses the term "cell culture" to include all forms of in vitro cultured cells, including ex vivo culture of donated tis- sues. Where the document refers more specifically to donor tissues, this is indicated.

\subsection{Background}

Following publication of an outline for cell and tissue guidance in 2002 (Hartung et al., 2002), a task force was convened to produce a GCCP guidance document that could be of practical use in the laboratory (Coecke et al., 2005). This guidance was established to serve the rapidly expanding use of in vitro systems - in basic research, to meet regulatory testing requirements for chemicals and products of various kinds, in medical diagnostics, and in the manufacture of a variety of products, including advanced therapies.

The 2005 document already foresaw further significant developments in the life sciences, and, in 2007, the outcome of a workshop to apply GCCP principles to human embryonic stem cells (hESCs) was published (Adler, 2007). Subsequently, in 2013, two OECD Working Groups (Working Group on Good Laboratory Practice (WG GLP) and the Working Group of the National Coordinators of the Test Guidelines Programme (WNT)) agreed to create a guidance document on Good In Vitro Method Practices (GIVIMP) for the development and implementation of in vitro methods for regulatory use in human safety assessment. That document, coordinated by the European Commission Joint Research Centre's Reference Laboratory for Alternatives to Animal Testing (EURL ECVAM), was published by the OECD (OECD, 2018). Later, two workshops were held, and a Steering Committee and Scientific Advisory Committee were formed under the auspices of the Center for Alternatives to Animal Testing (CAAT) (Pamies et al., 2017, 2018; Eskes et al., 2017) to consider the advances in "-omics" technology, stem cell research, and cell and tissue culture technologies that had evolved since 2005 and prompted the revision of the original document (Coecke et al., 2005) and the development of GCCP 2.0 (published as a draft and call for action in Pamies et al., 2020). The draft manuscript was reviewed by the Scientific Advisory Committee (SAC) (Appendix $8^{1}$ ) comprising various stakeholders. Their feedback and suggestions were carefully considered and incorporated into the final document that was endorsed.

This guidance is intended to support best practices in all aspects of the in vitro use of cells and tissues and to complement, but not to replace, any existing guidance, guidelines or regulations.

\footnotetext{
1 doi:10.14573/altex.2111011s
} 


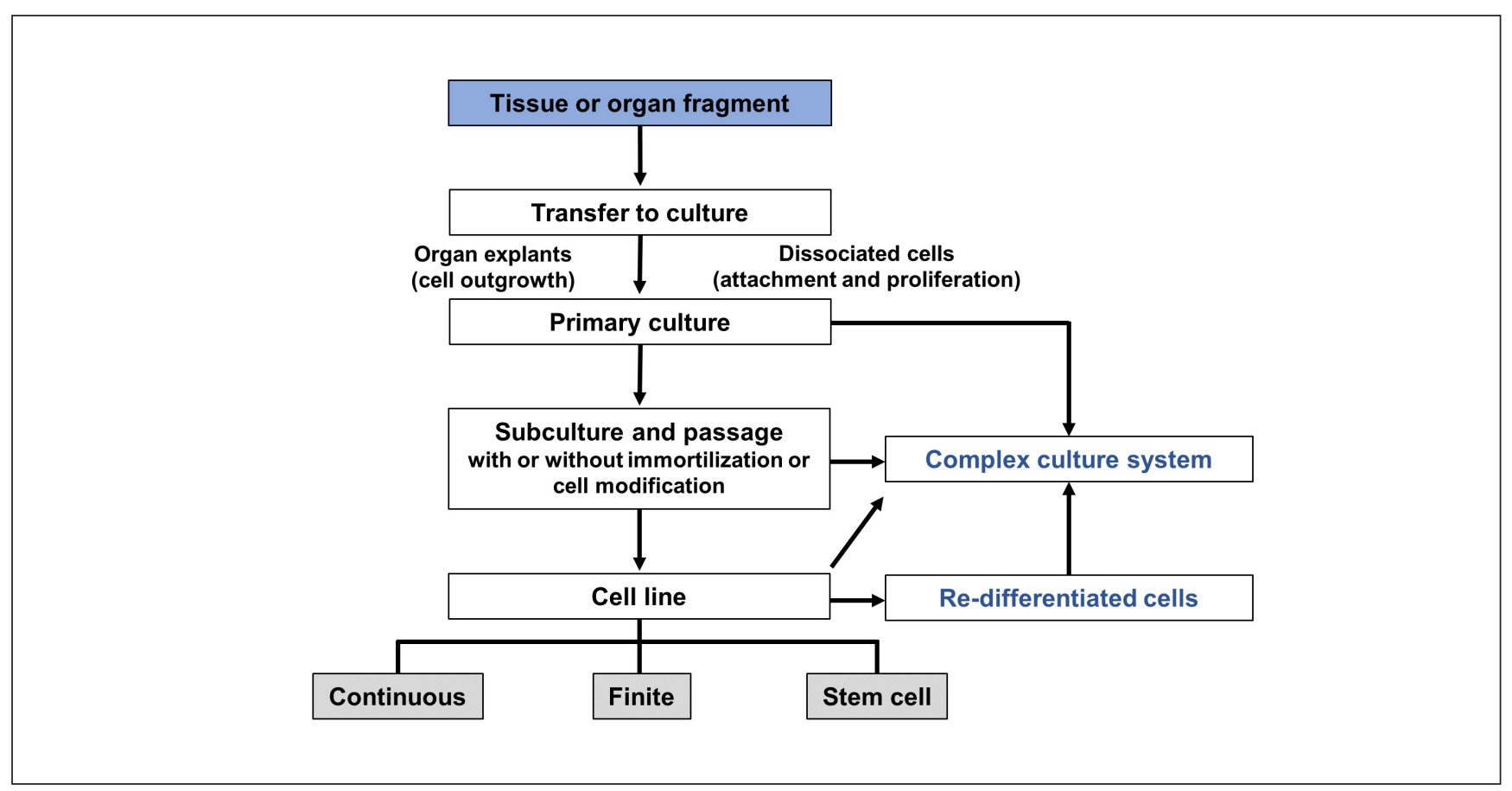

Fig. 1. Relationship between the main types of in vitro systems

\subsection{The principles of GCCP}

This GCCP guidance is based upon the following six operational principles:

1. Understanding your cell culture system and factors that affect it

2. Assurance of the quality in order to maintain the integrity, validity, and reproducibility of any work conducted, achieved by:

- assurance of the quality of all reagents, materials, equipment, cells, and tissues, and

- application of quantitative suitability criteria, validated with performance standards

3. Documentation and reporting of the information necessary to track the materials and methods used, to permit the repetition of the work, and to enable the target audience to understand and evaluate the work

4. Establishment and maintenance of adequate measures to protect individuals and the environment from any potential hazards

5. Compliance with relevant laws and regulations, and with ethical principles

6. Provision of relevant and adequate education and training for all personnel, and to promote high-quality work and safety

\subsection{The application of GCCP}

GCCP sets common standards for work involving cell and tissue cultures. It should be applied in life science research and development (to avoid poor reproducibility), in testing procedures in diagnostics, toxicology, and pharmacology (to meet regulatory requirements), and in the manufacture of products and therapeutic preparations of cells and tissues (to help assure safety and efficacy).
The application of GCCP must be consistent with any applicable regulations and requirements, and provide guidance generally not covered in requirements for specific applications. However, its implementation depends on the nature of the work involved. While this guidance is considered a minimum standard for the preparation and maintenance of cell cultures, deviations from its specific elements may be necessary under certain conditions, in which case they should be justified.

\section{Principle 1 : Understanding your cell culture system and factors that affect it}

There are three fundamental elements for assuring reliable, relevant, and accurate work when using cell- and tissue-based systems, which are:

- authenticity, including identity of the system - for example, provenance and confirmation of genotypic and/or phenotypic characteristics

- purity - for example, freedom from externally introduced cellular and microbiological contamination

- stability and functional integrity of the system in relation to its intended use

The standardization of in vitro systems begins with confirmation of the origin of the animal or human donor and the cells or tissues derived, and also embraces their subsequent manipulation, maintenance, and preservation, which may alter the characteristics of the cell culture. However, by establishing a framework of understanding and control procedures for certain factors, reproducibility, relevance, and reliability can be optimized. Chief amongst 
these factors is the availability of well-characterized and quality-controlled stocks of cells and tissues, media, and other critical reagents, as well as openly accessible defined procedures documenting, in detail, all the procedural steps taken. Several classifications have been published, which define different types of in vitro cell and tissue systems (Freshney, 2016; Geraghty et al., 2014; Schaeffer, 1990), and an overview is shown in Figure 1.

Four broad categories are considered in this guidance:

- isolated organs or tissues

- primary cultures and their passaged derivatives

- cell lines (including finite, continuous and stem cell lines, and their genetically and epigenetically modified variants)

- complex systems (including 3D, multicellular systems, transwell models, tissue reconstruction, self-generating organoids, microphysiological and organotypic organ-on-a-chip systems)

\subsection{Cells and tissues}

\subsubsection{Isolated organs and tissues}

Isolated organs and tissues, taken for direct use from animal or human donors, are used for a wide variety of in vitro applications. These systems are difficult to standardize because they often have complex environmental and nutritional needs and because of biological and experimental variables between donors and manipulation procedures. Such in vitro systems are popular due to their similarity to the in vivo (physiological) tissue. However, when carrying out experiments with such systems, a scientifically justified adequate number of experimental replicates is required to address variability in cell and tissue preparations, e.g., multiple tissue slices from the same sample and/or samples from multiple donors. Furthermore, the lifetime of these systems is limited, and characteristics can be rapidly lost with culturing time in vitro.

\subsubsection{Primary cultures and their passaged derivatives}

The initial in vitro culture of harvested cells and tissues taken directly from tissues or body fluids is called primary culture. A wide variety of solid tissue and organs can be used as a source of primary cells by enzymic, chemical or physical disaggregation. In many cases, such cultures exhibit key characteristics similar to those seen in vivo; thus, they are widely used for basic research and other in vitro applications. Some cells in primary cultures can proliferate and be subcultured (as early passage cultures). The term "passage" refers to the transfer of cells from one culture vessel to another or a number of vessels, usually with the aim of increasing cell numbers. Preparations of umbilical cord blood and bone marrow offer rich sources of stem cells and can provide the basis for a range of in vitro systems. However, they generally have a limited lifespan and are known to change important features with time in culture. They commonly require specific set-ups (Foty, 2011) and complex nutrient media, incorporating ill-defined and variable supplements (such as serum). However, serum-free and protein-free medium formulations are now starting to replace the use of fetal calf serum ${ }^{2}$ (OECD, 2018; van der
Valk, 2018). Primary cultures are typically composed of heterogeneous cell populations and are difficult to standardize and to reproduce because of variation between preparations, supplements, and donors. Using cell sorting techniques, specific subtypes of primary cells can be isolated that can often be cultured for a limited time or used in experiments immediately.

\subsubsection{Cell lines}

Cell lines are comprised of cells that are able to multiply for extended periods in vitro and can therefore be maintained by serial subculture, which enables the establishment of characterized and quality-checked cryopreserved cell stocks suitable for extensive in vitro experimentation (see Principle 2). Cell lines can be classified into a number of culture types (as illustrated in Fig. 1) that help to inform their handling and quality control due to different characteristics.

\subsubsection{Finite cell lines}

Finite cell lines are cultures of cells that can be sub-cultured many times but undergo a programmed process of biological "ageing" (Campisi and di Fagagna, 2007) and eventually cease replication and enter a state of senescence (Shay and Wright, 2000; Swim and Parker, 1957). Finite cell lines can have a lifespan of up to 70 population doublings in vitro. However, changes occur as they approach senescence, and they should not be used above the defined population doubling limits that can be established by experimental investigation (Hayflick, 1965). Many finite cell lines have been established from human fibroblasts, which may remain diploid for many passages.

\subsubsection{Continuous cell lines}

Continuous cell lines are defined by their apparent ability to be sub-cultured indefinitely. They do not show the senescence experienced with finite cell lines, as they evade natural ageing processes as observed in cancer cells. Historically, continuous cell lines have been typically derived from tumors or normal embryonic tissues. However, physical and molecular techniques have been developed to stimulate primary cells to replicate indefinitely. Each intervention to achieve this brings benefits but may also affect how closely the resulting in vitro model matches in vivo responses, as described in Appendix $1^{1}$. While some continuous cell lines appear to be stable over long-term passage in vitro, they often undergo substantial genetic changes (Geraghty et al., 2014). An authenticated cell line can evolve in cell culture so that the same cell line obtained from different laboratories can display different properties, including genetic heterogeneity (Ben-David et al., 2018; Liu et al., 2019; Kleensang et al., 2016). This can lead to a lack of reproducibility and comparability when working with the same cell line in different laboratories. It is therefore helpful to establish cryopreserved stocks ("master cell banks") of early-passage cells, which can be expanded to create stocks ("working cell banks") for use in experimental work. Continuous cell lines can comprise a heterogeneous mixture of phenotypes (e.g., HL-60, RD, SH5YSY) and

2 https://fcs-free.org/ (accessed December 7, 2021) 
may be able to differentiate upon adding certain molecules to the culture medium (e.g., retinoic acid, dimethylsulfoxide) or under specific culture conditions, such as being allowed to reach confluency (e.g., Caco-2, HT-29, LLC-PK, or MDCK).

\subsubsection{Stem cell lines}

In the culture and characterization of pluripotent stem cell (PSC) lines, there are a number of particular issues to consider, which relate to their nature, characteristics, and technical challenges for manipulation. Appendix $2^{1}$ describes these issues, and examples of detailed best practices for these culture types are outlined elsewhere (Andrews et al., 2015; Pamies et al., 2017; Pistollato et al., 2012; Stacey et al., 2016a; Adler et al., 2007; Tigges et al., 2021).

\subsubsection{Cell modification}

Isolated primary cells and cell lines can be subjected to modification other than immortalization, which may alter cell genetics and function.

\subsubsection{Direct reprogramming of cells and tissues}

Direct reprogramming of primary and passaged cells towards specific terminally differentiated cell derivatives has also been shown to be a promising approach to obtain cell cultures of interest (Zhang and Jiang, 2015) while avoiding the need to establish stable PSC lines and develop differentiation protocols. However, there is a range of different direct reprogramming methods, and as these undergo refinement and optimization, current best practices should be reviewed and implemented. The use of direct reprogramming as a source of routine cell supply for experimentation is an area in expansion (Xu et al., 2015).

\subsubsection{Genome editing and gene expression regulation}

There is now a range of genome- and epigenome-editing techniques (reviewed by Pamies et al., 2018), as well as regulation of gene expression by knock-out/in and RNA interference (RNAi) techniques or introduction of other genetic vectors. These technologies facilitate studies of the role of genes in normal and disease states by intervening on the state or expression level of specific genes. This is particularly relevant in the study of monogenic diseases, for which the genes responsible for disease etiology are known (Pamies et al., 2018). However, the application of gene editing still requires careful quality control and is associated with several uncertainties (e.g., off-target effects on genome integrity, indirect effects through chromatin remodeling, unintentional changes of the primary genetic code, etc.).

RNAi technologies are based on the introduction of double-stranded RNA (dsRNA) into the cytoplasm, which triggers the cell to down-regulate certain RNAs. Due to its specificity and simplicity, this approach is now widely used to knock down the expression of specific genes. It should also be considered that RNAi technologies (such siRNA or shRNA) may have an impact on the induction of the cellular anti-viral response (Berkhout, 2018), which may confound the interpretation of downstream experimental data.

It is important to control gene silencing experiments by adopting appropriate controls including negative (RNAs which do not target any gene) and positive controls (RNAs that are known to give robust gene silencing). Furthermore, it is important to recognize that gene silencing tools may cause unintended or off-target effects such as induction of anti-viral responses that can impact on experimental data. This can be controlled by use of more than one RNA sequence for a single target. In the development of genome editing technologies used in disease modelling and drug development, a panel of techniques has been established (i.e., TALENS, CRISPR-Cas9 and Zinc-finger techniques), each one presenting different strengths for particular applications. The quality of the models generated by these techniques may depend on a variety of factors explored in Principle 2 (see 2.3). As an example of the most commonly used technique, CRISPR-Cas 9 impacts on quality include: an undefined level of off-target effects of designer nucleases, purity of the Cas-9 protein, constitutive expression of Cas-9, genetic stability of edited clones, and retention of wild-type cells (Hendriks et al., 2016). The analysis of several gene-edited clones and their functional derivatives or the creation of isogenic control cells can help resolve these issues.

Genetically and epigenetically modified cultures may also be created using recombinant vectors for a number of purposes, including secretion of complex biological molecules, generation of altered biological states, and expression of reporter molecules when certain pathways are activated or cell lineage states are achieved. In the development of these lines, it is important to consider whether the proposed constructs and their locations in the genome would be likely to impact the intended functionality and utility of the cells (for a review, see Stepanenko and Heng, 2017), altering, for example, the constitutive expression of reprogramming factors in PSCs or silencing a reporter gene that is supposed to remain active.

Gene-editing, vector transformation, and other stable interventions can generate large numbers of modified cells with different integration sites or other features that may affect their expression and the utility of the different clones for their intended use. Thus, it is important to establish a panel of cryopreserved stocks of such clones so that they can be compared and the most useful clone selected (WHO, 2010).

Here we have simply mentioned some relevant features of the more common genetic engineering techniques, and further details on acceptance criteria to address the scientific validity and quality of such cell and tissue cultures are given in Principle 2 and Appendix $3^{1}$.

\subsubsection{Cell fusion}

Cell fusion is a common event in normal animal development, but it is also implicated in disease (Ogle et al., 2005; Davoli and de Lange, 2011; Aguilar et al., 2013). It can be induced in vitro to yield cell cultures that are of value in research into somatic, malignant, and developmental processes and has useful applications in cell-based manufacturing, such as the production of monoclonal antibody-secreting hybridomas (i.e., fusion of an antibody-producing cell with an immunocytoma cell) and some cell-based cancer therapies. A wide range of techniques, includ- 
ing chemical induction (e.g., polyethylene glycol), electrostatic charge (electrofusion), and viral and other fusogens (Hernandez and Podbilewicz, 2017) can be used to create fusion cell lines.

Cell fusion and the creation of cell hybrids can generate complex and diverse combinations of cellular composition from different cell types, and even different species, that will potentially bring together functional and possibly competing structures, organelles, biochemistry, and genetic mechanisms in the same derivative cell. The impact of these changes may be difficult to predict, and workers should investigate the relevant literature to identify suitable parameters for their characterization (see Appendix $3^{1}$ ).

\subsubsection{Complex culture systems}

Complex culture systems are a diverse group of technologies aimed at providing in vitro paradigms for tissue function, e.g., multicellular trans-well models, bioprinted models, spheroids, organoids, microphysiological systems, and organotypic organ-ona-chip models (Pamies et al., 2017). They may include several cell types in co-culture, such as blood-brain barrier models incorporating endothelial and glial cells, pericytes and neurons, or liver models with hepatocytes and stellate, Kupffer and endothelial cells. Also, they can be combined with engineered biomaterials and devices (e.g., microfabrication/chips, microfluidics, and microelectronics). These models may also simulate natural tissue perfusion and shear forces in circulatory systems while allowing the observation and real-time monitoring of the microtissue.

Cells grown in complex culture systems are reported to achieve a more advanced state of morphological and functional maturation than cells in monolayer culture, such as the deposition of extracellular matrix, secretion of growth factors, altered cell proliferation, morphological development, lineage differentiation, changes in gene expression levels (Mabry et al., 2016), rate of cell death (Bonnier et al., 2015), or cell migration (Duval et al., 2017). Thus, complex systems may exhibit features not previously observed when the same cells are cultured using standard methods, which could impact on the required media composition, culture controls (e.g., gas, nutrients, catabolites), measurements required for culture monitoring/suitability (e.g., morphology/structure, cell enumeration, function), even laboratory safety issues (e.g., reactivation of endogenous virus, unexpected growth of contaminants), and safety of recipients of medicinal products made using cell culture (e.g., contamination or acquisition of tumorigenic properties). Recent developments in automation allow accommodation of complex culture systems in automated screening applications (Carragher et al., 2018). The generation of intricate culture systems is challenging, requiring complex protocols and skills, and demands specialist training or staff (see Principle 7).

\subsection{Cell identity, stability, and sustained functionality}

\subsubsection{Cell identity}

Cross-contamination between different cell lines is a serious but often neglected problem (Nelson Rees et al., 1981). It is one of the most well-known causes of irreproducible research data that can lead to withdrawal of publications and wasted time and effort (Casadevall et al., 2014; Freedman et al., 2015). Wherever possible, cells should be obtained from certified sources, and appropriate procedures should be applied to minimize the risk of cross-contamination and mislabeling during their storage and use in the laboratory. Cells should be authenticated and their identity established at the earliest opportunity following receipt into a laboratory. The techniques for testing identity of cell lines of both human and other species are discussed in Principle 2.

Another important feature of cell identity is the cell line name (Reid, 2017). The same cell line may be referred to by different names by different authors, and differing cell lines have also been called the same name (Luong et al., 2011). Numerous attempts have been made to establish a standardized nomenclature for naming cell lines; some standardization has been used in specialist areas such as for PSC research in hPSCreg (Kurtz et al., 2018) and for general cell lines through the use of Research Resource Identifiers (RRIDs) (Babic et al., 2019). However, it has been difficult to harmonize cell naming across the field of cell culture users.

\subsubsection{Stability of in vitro culture}

As already discussed, phenotypic heterogeneity in cell cultures may occur between different passages. Additionally, more significant and permanent changes can arise due to the emergence of variant clones during expansion and/or differentiation procedures. Genetic and epigenetic variants are known to arise in the derivation of a cell line and during cell culture expansion, notably in cancer cell lines and PSCs (Rebuzzini et al., 2016). Genetic variants may exhibit a number of changes including point mutations, small deletions, rearrangements, inversions, gene amplifications, and chromosome loss or aneuploidy, but it is typically difficult to predict their impact on functionality or patient safety in clinical applications (O'Shea et al., 2020). Such changes appear to occur at any time during passage (International Stem Cell Initiative, 2011) and may be associated with culture conditions - such as medium acidification - as a consequence of suboptimal culturing and passaging (e.g., frequent single cell dissociation) or the repeated use of Rho kinase inhibitors (Assou et al., 2018; Jacobs et al., 2016).

\subsection{Influence of reagents and environment on cells}

\subsubsection{In vitro culture medium components}

Cell and tissue culture environments differ in many respects from those found in vivo. Key elements of in vitro culture conditions include culture media, medium additives, osmolarity, gas atmosphere, temperature, $\mathrm{pH}$, and the matrix on which the cells grow. Other factors may also impact on cells. These include vibration, light exposure, leachates from plastic cultureware, and volatile and/or toxic compounds in the laboratory air.

\footnotetext{
3 http://www.hpscreg.eu (accessed December 7, 2021)

4 https://web.expasy.org/cellosaurus/ (accessed December 7, 2021)
} 


\subsubsection{Basal medium}

In vitro work is generally performed using complex nutritive media. Many slightly different versions of standard formulations, such as Minimum Essential Medium (MEM) and RPMI 1640, are available for specific cell types (Freshney, 2016; Price, 2017). Depending on the circumstances, the basal culture medium may be serum-supplemented, but increasingly serum-free media supplemented with additives are used ${ }^{2}$ (OECD, 2018; van der Valk, 2018). It is important to recognize that even subtle changes in the medium formulation (e.g., glucose concentration, presence of HEPES) can substantially alter the characteristics of certain cells and tissues. Therefore, it is critical to document which variation of standard basal media is being used for a particular cell culture. Media with carbonic acid buffer systems require carbon dioxide in the cell culture atmosphere to support optimal pericellular $\mathrm{pH}$, but media with other buffer systems may not have this requirement.

\subsubsection{Medium additives}

Animal sera present several limitations, mainly associated with their complexity: lability, viral contamination (potentially with multiple viruses), and batch-to-batch variability (Brunner et al., 2010; Gstraunthaler, 2003; Nims and Harbell, 2017). Plating efficiency tests may be necessary to assess new batches before purchase (Freshney, 2016). Serum may also need to be checked for the presence of undesirable components (e.g., immunoglobulins, endotoxins, hemoglobin) and irradiated to reduce viral load. The use of human serum carries the risk of human pathogenic viruses, and consideration should be given to replacing it with chemically defined alternatives.

The inherent disadvantages in the use of animal and human sera have stimulated the development of alternatives, including some equally ill-defined supplements (e.g., human platelet lysate, pituitary extracts, chick embryo extracts, bovine milk fractions or colostrum, and various plant extracts, such as "vegetal serum"). Serum-free preparations containing purified growth factors and hormones sometimes supplied as additive "cocktails" are now increasingly used, along with chemically defined protein-free media for cell passage and differentiation. Such formulations reduce the need for serum-based cell culture media and therefore significantly reduce the risk of microbial contamination, improve standardization of cell culture experimental work by decreasing biological variability, and reduce the need for batch pre-use testing.

\subsubsection{Nutritional status}

The exhaustion or inactivation of essential nutrients in cell culture media and rising levels of catabolites will inhibit cell growth and cell function, ultimately leading to cell death. Different medium supply schemes such as static, perfusion or periodical may also influence the proliferation characteristic of the cells (Gilbert et al., 2019). Planning an appropriate procedure for medium replenishment (i.e., frequency and volume of medium) and passaging (e.g., split ratio) is therefore essential. This should also be considered when using conditioned medium from one culture to promote the growth of another, as high proportions of condi- tioned media can inhibit rather than promote cell growth. Millifluidic- and microfluidic devices and automated perfusion bioreactor systems allow short-interval or continuous medium renewal and may help avoid these issues (Serra et at., 2012). Use of "flexible-feeding" hPSC media, which allow users to perform a double feed and skip a medium change the next day, are now available, however these should be used with care and not as a routine occurrence due to possible impact on phenotype. Before initiating intensive experiments, users should consider how recently cell cultures have had medium replenished, as nutritional depletion and/or buildup of waste can impact phenotype and experimental outcomes.

\subsubsection{Antibiotics}

While antibiotics (e.g., gentamycin, ampicillin, ciprofloxacin) are effective against bacteria, they may also impact fundamental aspects of eukaryotic cell biology, possibly causing cytostatic and/ or cytotoxic effects in animal cells (Lanbeck and Paulsen, 1995; Lanbeck and Paulsen, 2001). Not surprisingly, antifungal agents like amphotericin B that target higher-order eukaryotic micro-organisms are likely to be more toxic than other antibiotics to animal cell cultures. Many microorganisms may be inhibited (but not killed) by some antibiotics and may also develop resistance. Contamination due to poor antiseptic routines can often result in higher mycoplasma incidence in cultures grown with common antibiotics, which may eradicate easily detectable bacteria but leave mycoplasma unaffected. When the use of antibiotics becomes routine in the cell and tissue culture laboratory, it can result in widespread suppressed contamination of cell stocks, which may only become evident when antibiotics are removed. However, contamination with mycoplasma may remain undetectable without a specific test. Such contamination may still affect in vitro research data. Given these significant issues, it is generally considered good practice to avoid the use of antibiotics and antifungal agents except in well-justified cases, e.g., to protect rare/unique tissues, to disinfect organ and primary cultures that are likely to be heavily contaminated, and to positively select recombinant cell clones. General use of antibiotics should not be necessary where staff has been adequately trained to use aseptic techniques (see GCCP Principles 5 and 6). The use of closed cell handling systems can also reduce the need for antibiotics by reducing microbial risks.

\subsubsection{Cell culture surface, matrix and feeder cells}

A variety of extracellular matrix extracts and proteins (e.g., Matrigel ${ }^{\circledR}$, vitronectin, fibronectin, laminin, collagens) can be used to coat plastic surfaces to make them more hydrophilic and promote cell adhesion by specific binding to ECM molecules. Other modifications may be used to prevent adherence of suspension cultures. Synthetic nanofiber polymers and scaffolds have been developed to mimic the 3D in vivo niche and enhance cell phenotype. Such systems also have greater stability and reduced batch-to-batch variability when compared to biological substrates that may require pre-use batch testing.

The preparation method for coating materials may lead to toxic conditions, such as low $\mathrm{pH}$, thus washing before cell seeding may be necessary. The use of commercially available pre-treated 
and pre-coated plastic vessels can help avoid these washing steps. The type of matrix can significantly influence the functionality of a particular cell type and differentiation of progenitor and stem cell cultures, therefore selection of appropriate sources with assured reproducibility is important. Moreover, medium and matrix may need to be selected carefully to complement each other in order to obtain the desired culture characteristics.

Tissues or organ fragments can be perfused with physiological buffers, or cells from disaggregated tissues allowed to reaggregate (Scarritt et al., 2015) using a variety of procedural steps and/or devices. Moreover, numerous cell types, including many primary cultures, require co-culture with feeder cell layers that are mitotically inactive to enable development of optimal growth, functionality, and stability. Feeder cells should also be subjected to GCCP, and, in addition, consideration should be given to an appropriate seeding ratio of feeder cells and the cell culture. This may impact on optimal expansion and differentiation. In addition, where PSCs are passaged in feeder cells, they may need to be isolated from feeder cells prior to differentiation toward specific cell lineages. Nowadays, most PSCs are routinely passaged in feeder-free conditions due to developments in culture media and new synthetic coatings (Villa-Diaz et al., 2013).

\subsubsection{Physical environmental conditions}

\subsubsection{Temperature}

The optimal culture temperature depends on the type of cells involved, and incubation at suboptimal temperatures may at least temporarily alter the characteristics of the culture. Insect and fish cells tend to require a relatively low optimal growth temperature compared to mammalian cells. The exposure of mammalian cells to temperatures above $39^{\circ} \mathrm{C}$ may induce heat shock response and apoptosis, while growth below $35^{\circ} \mathrm{C}$ typically slows replication and alters gene expression. Thus, ensuring a stable prescribed temperature for cultures is often important to assure reproducible biological functionality. It may also be important to use prewarmed media to avoid cold shock. The use of certain fluidics (micro- as well as millifluidics) and bioreactor systems operating under perfusion modes permits automated medium change. Closed, controlled-temperature cell handling systems can reduce suboptimal transient temperature excursions that can stress cells and contribute to edge effect in 96-well plate assays (Darou et al., 2019). Some modified cell lines may require incubation at different temperatures for different purposes, such as for elimination of recombinant Sendai virus vectors and to regulate the growth rate of cell lines expressing the temperature-sensitive form of SV40 large T-antigen. Thus, ensuring a stable temperature for cultures is important to assure reproducible biological functionality.

\subsubsection{Atmosphere}

Oxygen and carbon dioxide are known to be vital for cell growth. Variations in the levels of these gases can have significant effects on cell cultures. Room air conditions are hyperoxic, hypocapnic, and cold for cells in culture. For both gases, high levels will be toxic, and low levels may inhibit cell growth and/or cause significant changes in gene expression (Majmundar et al., 2010). For many cell cultures, the commonly used atmosphere is $5 \% \mathrm{v} / \mathrm{v}$ carbon dioxide in air, but the optimum carbon dioxide concentration will depend primarily on the buffering system of the culture medium and the desired features of the cell culture.

Oxygen levels may need to be optimized for specific purposes, for example increasing oxygen availability in large-scale bioreactors. Reduced oxygen tension can have a significant impact on cell culture phenotype and is considered beneficial for the culture and differentiation of PSCs (Ivanovic, 2009; Jez et al., 2015; Pamies et al., 2013). It is known that native tissue oxygen concentrations can be between 1-5\% (Ottosen et al., 2006; Wenger et al., 2015; Keeley and Mann, 2019). Such oxygen levels may be important for various cell types. In particular, they promote self-renewal of a number of stem cell types, increase efficiency of reprogramming to induce pluripotency (Hawkins et al., 2013), and have been shown to be important for PSC fate specification (Hawkins et al., 2013). Careful control of atmosphere and factors affecting gas diffusion in culture medium, therefore, is essential, and it is important to be aware of situations causing oxygen level fluctuations, such as medium change, processing, and passaging, and to minimize the periods of such fluctuations. In addition, the height/level of medium above cells determines the accessibility to oxygen and should be recognized as an important factor for cell culture (Al-Ani et al., 2018). The use of closed cell handling chambers to provide constant physiologically relevant oxygen can improve cell function (Mount et al., 2019; Wong et al., 2020).

\subsubsection{3 $\mathrm{pH}$}

The optimal physiological $\mathrm{pH}$ for mammalian cell cultures is considered to be $\mathrm{pH} 7.3 \pm 0.1$ and $\mathrm{pH} 6.0$ for insect cells. Variation outside a relatively narrow $\mathrm{pH}$ range may have significant effects on cell phenotype, growth, and viability. Media containing $\mathrm{pH}$ indicators, such as phenolphthalein, which changes color with changes in $\mathrm{pH}$, are often used to give warning of adverse culture state or contamination. On the other hand, $\mathrm{pH}$ indicators may affect the phenotype and functionality of specific cell types and may interfere with downstream assay readouts, e.g., phenol red is known to have some endocrine disrupting effects (Berthois et al., 1986). In some media, HEPES is used to make the $\mathrm{pH}$ more stable. This may be advantageous for cell cultures where the addition of various compounds is anticipated, which may differently affect medium $\mathrm{pH}$ (e.g., in toxicological and pharmacological assays). It should, however, be kept in mind that for some cellular processes it is necessary for the cells to affect extracellular $\mathrm{pH}$. The use of media with fixed $\mathrm{pH}$ in such settings may, therefore, not be optimal.

\subsubsection{Osmolarity}

Cell culture media have typically been designed to mimic the osmolarity in serum (290 mOsm) and are usually 290 $\pm 30 \mathrm{mOsm}$. However, the osmolarity in other tissue systems, such as kidney medulla, liver, and embryos, is quite different, and the optimal conditions for culture of cells from these tissues may also differ. In addition, the use of hormones in cell culture media may also require adjustment of osmolarity to achieve optimal cell func- 
tion. The osmolarity of even a single medium type, such as MEM made in different laboratories, can vary considerably; this can arise due to unwitting use of differently hydrated salt preparations at the same molar concentration (Waymouth, 1970).

\subsection{Handling and maintenance}

Care should be taken not to expose the cells or tissues to inappropriate or unintended variations in conditions (e.g., extended periods out of the incubator or violent shaking). Key items of equipment, including incubators, laminar air flow cabinets (for sterile media preparation only), Class II Biological Safety Cabinets (BSCs), and cryostorage systems, must be set up and used appropriately (see Principle 2 and Appendices 4 and $6^{1}$ ). The use of closed cell handling systems can eliminate exposure of cells to non-physiologic room air conditions for cell handling. Aseptic technique is vital during medium changing and passaging or other open processes. Initially, handling and maintenance protocols for cells and tissues should be established based on procedures provided by the cells' supplier.

The term "passage" refers to the transfer of cells from one culture vessel to another or a number of vessels, usually with the aim of increasing cell numbers. Typically, passaging is performed when the cells are still in the exponential growth phase. Cultures with high viability and close-to-peak viable cell concentration (suspension cultures) or confluency (adherent cultures) are selected for passage to optimize the expansion of cell numbers. Cell culture "age" has historically been estimated by recording the cumulative number of passages. However, this approach fails to take into account the population doublings, which are influenced by the passage manipulation method, operator, medium, and culture surface (see Principle 2). In addition, simple dilution of cells at passage may not necessarily give reproducible seeding density and therefore may contribute to variation between passages.

In order to avoid contamination of cell culture work, a range of measures can be adopted (Lincoln and Gabridge, 1998; Stacey, 2011), including:

- laboratory layout and procedures that reduce risk of accidents and avoid colocation of work or materials that are known to be clean and those known or likely to be contaminated

- quarantine of new and untested materials

- maintenance of a routine laboratory cleaning program and safety cabinet disinfection after individual periods of cell culture work

- planned quality control of preserved cell stocks and where necessary (e.g., sterility testing, mycoplasma testing)

- staff training in aseptic technique, minimal use of antibiotics, appropriate routine cleaning, disinfection procedures, and disposal of waste

- It is recommended that all individual users within a particular research group should have their own working stocks of cell culture medium and reagents to limit variability and potential for contamination.

\subsection{Cryopreservation, storage, and shipping}

Cells and tissues can be cryopreserved in a stable state for limited or prolonged periods (Baust et al., 2017). All elements of the cryopreservation process, including culture selection, cryoprotectants, cooling rate, storage, and recovery, are important for success, and key issues are given in Appendix $5^{1}$ (for a more detailed review see Stacey et al., 2016b).

Storage in the liquid phase of nitrogen provides the most stable storage environment, although vapor phase storage is generally considered to be safer (see Principle 5) and is advised to eliminate the chances of transfer of materials between vials, which can occur in the liquid phase of nitrogen. Electrical storage systems provide a very practical and maintenance-free, low-temperature storage solution, but in the absence of liquid nitrogen or carbon dioxide back-up systems they are at high risk in the event of loss of power supply. Where there is multi-user access, any storage system will be prone to temperature cycling, which is known to reduce viability (Angel et al., 2016), and the failure of routine liquid nitrogen refilling procedures can result in the catastrophic loss of viability of stored materials.

Concerning cryopreservation of PSCs, "vitrification" of a colony by cutting of differentiated adherent cells has been routinely used in some laboratories, though it can be technically challenging. Controlled-rate freezing of cell suspensions or small aggregates provides an acceptable preservation strategy for PSCs for which preservation reagents (e.g., CryoStem ${ }^{\mathrm{TM}}$ Freezing Medium, StemGent; Synth-a-Freeze ${ }^{\circledR}$ Cryopreservation Medium, ThermoFisher; Cryostor, Biolife) and freezing equipment (e.g., CoolCell or controlled rate freezers) are available (for a detailed review, see Awan et al., 2020). Commercial preparations are chemically-defined and ready-to-use and may therefore present an advantage to improve cell recovery and viability after thawing from cryostorage.

\subsection{Microbial and viral contaminations}

Contamination with microorganisms and viruses can result in the catastrophic loss of cultures, and contaminations may potentially spread and infect other cultures, lab personnel and operators in a laboratory (Uphoff et al., 2010). Undetected contamination with slow-growing microorganisms or with microorganisms that are resistant to antibiotics can have a significant impact on the quality and/or validity of data obtained from in vitro systems (for further comments on the use of antibiotics, see 1.3.1.4). The most common examples of such infections are environmental bacteria, fungi, and mycoplasma, the latter arising most frequently from new cell lines introduced to the laboratory (Drexler and Uphoff, 2002). In cell culture, there are also various potential sources of viral contamination, including the operator, cell culture reagents of animal origin, cells or tissues of human origin (including feeder cells), and even contamination derived from liquid nitrogen storage vessels (Fountain et al., 1997; Grout and Morris, 2009; Morris, 2005). All cell and tissue culture facilities should therefore take appropriate measures to minimize the risk of microbial and viral infections and implement appropriate testing. Note that visual assessment is not sufficient, and daily medium change with defined serum-free medium can repress contaminations to levels only detectable using a TSB/FTB broth inoculation (O'Shea et al., 2020). The use of closed cell handling systems can reduce microbial risks from cell handling. Viruses can cause lytic infec- 
tions and destroy the host cells. However, they may also establish persistent sub-lethal infections that are maintained with passage of the host cell line, although many cell lines both carry and express virus sequences without producing infectious virus particles. In a small number of cases, human infectious pathogens are released into the culture medium, such as Epstein-Barr virus from transformed B-lymphoblastoid cell lines. Animal viruses are expressed by some cell lines whilst causing no microscopically apparent adverse effects, including bovine viral diarrhea virus in certain bovine cell lines. A number of human cell lines appear to be infected with viruses, including human pathogens such as HTLV-2 (Uphoff et al., 2019). Mammalian genomes also contain many retrovirus-like sequences, which, whilst not overly infectious, may be released in large quantities as retrovirus-like particles by murine myeloma cells, hybridomas, $\mathrm{CHO}$ cells, and BHK cells. The expression of such virus-like sequences is also observed at the RNA level in many human cancer cell lines and also in non-human primate cell lines. Rarely, prion agents may also be maintained in vitro in different cell types - a particularly challenging issue when cells are intended for the development of cell therapeutics (Falsig et al., 2008; Lawson et al., 2008; Krejciova et al., 2017).

\section{Principle 2: Management of quality in order to maintain the integrity, validity, and reproducibility of any work conducted}

\subsection{Quality management}

Quality management (QM) for GCCP is used here as a generic term that comprises measures and procedures implemented to provide consistent quality of cell cultures (and data therefrom) and to detect potential mistakes and errors. QM, as defined here, contains elements of quality assurance and quality control, i.e., processes to prevent and to detect suboptimal quality outcomes. Notably, we do not refer here to strict technical definitions, as laid down in ISO 9000 or the GLP rules. GCCP absolutely requires QM considerations, but the exact rules and ways of implementation depend on the laboratory, project, and research context. Some of the key principles that need to be considered are 1) traceability of the work, 2) sustained use of agreed procedures and quality criteria, and 3) a proactive process for managing quality issues and monitoring of adherence to rules that have been established. More standardized procedures including, e.g., inspections to check compliance, can be found in the GIVIMP document (OECD, 2018)

QM is important in all aspects of cell and tissue culture, including the materials used, equipment, the laboratory environment, and maintaining staff competency. Of the materials used in cell culture work, those which come into direct contact with the cells or tissues should receive special attention regarding their potential to influence cell culture properties. Equipment should be suitable for its intended use, and appropriate quality assurance procedures are necessary for the purchase, installation, commissioning, correct use, performance monitoring (for example, calibration), and maintenance of the following:

- low temperature storage refrigerators

- incubators

- laminar air flow and safety cabinets, and other sterile work areas

- automatic pipettes and pipettors

- sterilization ovens and autoclaves

- analytical and production equipment

In many formally regulated environments, staff awareness of safety issues and technical procedures is organized under a formal quality assurance framework, where compliance and staff competence are monitored. In research laboratories, formal quality assurance may not be implemented in the same way, but formal procedures should exist for data reporting (see Principle 3) and laboratory safety training where non-compliance and accidents should be monitored (Principle 6).

Quality control (QC) may be thought of as a series of checkpoints designed to confirm the quality of the work at each stage, highlighting quality problems so that they can be managed appropriately.

Routine QC tests are most effective when built into methods/ protocols/SOPs to ensure predefined requirements as described by Krebs et al. (2019). In this document, GCCP Acceptance Criteria $(\mathrm{GAC})$ are described to assure that only reliable data are used. GCCP describes different kinds of acceptance criteria, broadening the scope from the definition of acceptance criteria used in GIVIMP (OECD, 2018) ${ }^{5}$.

Monitoring and review of QC data can also be of great value in detecting sudden changes or undesirable trends. Even if the values are still within the acceptable range, a progressive trend may be an early indicator of underlying problems. Such reviews can also be used to facilitate investigations to reveal the root causes of suboptimal cell systems. Examples of such acceptance criteria are cell morphology and doubling time, which can give an indication of fundamental underlying changes to cell biology (see 2.3). Historical data, including information in the scientific description of the cell system (see 2.2.1), can provide a useful reference and should be included in QC staff training.

Key components of a QM would be:

- assuring that all the materials (including cells and tissues) and equipment used are suitable for their intended purpose

- assuring that all materials are appropriately handled, stored, and used within the expiry date

- monitoring batches of certain materials with regard to changes or variations that may affect their use (this is important for certain critical reagents, such as serum, where pre-use testing may be necessary).

\footnotetext{
5 Definition of GIVIMP acceptance criteria: "Criteria for when study results can be accepted, i.e., a set of well-defined parameters describing aspects of the in vitro method such as control and reference item output, acceptable range for positive and negative controls, etc. These should primarily be established based on information from existing data on the finalized in vitro method or described in relevant bibliographic data. However, relevant development data obtained on a version of the in vitro method equal to the one used for generating the study results, as well as historical data, may need to be taken into account where available."
} 


\subsection{Quality control testing}

\subsubsection{Cells and tissues}

A scientific description of each cell or tissue culture, stating how it was created, species, and tissue of origin, special features, culture conditions, etc. (see Principle 3), is important for identifying key features (Principle 1) for QC and to set GAC for the testing of the tissue, cell line, or complex systems used (see Principle 2.3). Cells and tissues arriving in the laboratory will usually need to be quarantined until essential quality checks have been performed for likely contaminants (typically bacteria, fungi, mycoplasma, and viruses). Importantly, an early risk assessment, as part of completion of the aforementioned scientific description, is also valuable to highlight any other necessary precautions and testing (see Principle 5). Many of the issues discussed here are expanded in Section 5 of GIVIMP (OECD, 2018).

If appropriate documentation is not provided with a new cell system, then the laboratory will need to implement rigorous processes for checking the identity, characteristics, and stability of the cell and tissue cultures. After initial expansion of the culture, some vials are typically frozen down and stored as a "token stock" to provide security against loss of the culture. From the token stock, a master cell bank (MCB) is prepared. The MCB may then be used to produce working cell banks (WCBs) comprising an adequate number of vials within acceptable passages / population doubling level (PDL) to supply the early anticipated level of use (Tigges et al., 2021). Where cell clones are generated from a single original culture, these may be established as pre-master banks and treated similarly for QC purposes as a token stock (see Tab. 1) before selection of a clone for the preparation of an MCB.

Table 1 details quality checks to be performed throughout the cell culturing and harvesting lifecycle. QC testing may be focused on the MCB to assure the cell culture has retained its key features and has not become contaminated. The WCBs may be subjected to more limited testing, typically determination of viability and verification of absence of mycoplasma, other bacteria, and fungi, but it may be wise to include stability testing, depending on the cell culture and criticality to the work. The original scientific description of the cell culture (see above) may also indicate the need for additional tests; for example, genetically engineered cultures may need to be tested for the integrity and stability of the genetic modification, copy number of modified sequences, and stability of expression where appropriate. It is recommended to develop acceptable intervals for periodic testing to confirm the genetic and phenotypic stability of the cell system; these, however, can be highly case-dependent (Blazquez-Prunera et al., 2017; Daily et al., 2017; Meza-Zepeda et al., 2008). It may not always be feasible to assess all these characteristics, as some may be limited by practical considerations (such as significant time and resource implications).

Cell line identity testing should be performed on in-house cell cultures and be based on short tandem repeats (STR). DNA profiling can be carried out in-house or by service providers with the ability to compare STR results between organizations (International Stem Cell Banking Initiative, 2009). Prompt authentication of any new cell culture received in the laboratory is important, and this is best performed using a direct comparison with the original tissue or parental cell culture (in the case of PSCs and genetically modified cell lines) (Tigges et al., 2021). In the absence of such material, the STR profile may be compared with that obtained by the original developer of the cell line, other researchers working with the same cells, or by consulting the ICLAC database or CLASTR (Cellosaurus STR similarity Search Tool) ${ }^{6}$ (OECD 2018). STR methods are also available for some animal species. Cytochrome C oxidase subunit 1 (COX1) gene sequencing is used for a wide range of organisms, and large databases of reference sequences are available, for example, the boldsystems. org database ${ }^{7}$. Other techniques may also be utilized, including aldolase gene intron PCR, isoenzyme analysis, and karyology (International Stem Cell Banking Initiative, 2009).

Cell line authentication or "barcoding" is recommended for human-derived or animal-derived cell lines, e.g., CHO cell lines, where genomic information is available for sequencing or PCR applications. Where such methods are not useful, a selection of other appropriate phenotypic, genotypic or functional markers should be used, e.g., for the use of flow cytometry or immunofluorescence (Capes-Davis et al., 2013). Moreover, it is important to screen cell cultures to identify the presence of unwanted genomic variants, e.g., cross-contamination by different cell lines or genetic drift. The selection of a single technique is not straightforward because the available techniques differ in methodological approach, size and comprehensiveness of the genetic changes they can detect, and sensitivity for low-level variants. Commonly used genomic integrity tests include targeted assays (fluorescence in situ hybridization (FISH) and PCR-based nucleic acid quantification approaches, such as quantitative real-time PCR and digital PCR), as well as whole genome assays (G-banding karyotyping, chromosomal microarray and massive parallel sequencing) (MacLeod and Drexler, 2005; Capes-Davis et al., 2010; Dirks et al., 2009). Depending on the PDL needed in the final cell product, the batch-release tests can be completed by regular in-process testing to avoid investing time and efforts in the production of a cell line that was compromised by an early genomic alteration. Concerning cell identity and stability, large-scale testing for batch release, such as massive parallel sequencing, should be considered to determine the baseline genomic status and to identify gene variations of donor versus acquired origin. Such procedure would help to interpret the batch-release test results and to track samples from the original donor material, early-passage cells, or parental cell culture to the final batch product.

Testing for microbiological contamination should be performed for the most likely contaminants of a cell culture. There are many different methods available to test for contaminations (Baumstummler et al., 2010; Coté, 2001). Bacteria, fungi, and mycoplasma can be detected from culture cells and supernatants or tissue media by established Pharmacopoeia methods based on

6 http://iclac.org (accessed December 7, 2021)

7 http://www.boldsystems.org (accessed December 7, 2021) 
Tab. 1: Quality checks on cell culture harvesting stages (OECD, 2018)

\begin{tabular}{|c|c|c|c|c|}
\hline Attributes & Original source ${ }^{i}$ & Token stock ${ }^{j}$ & Cell banks ${ }^{k}$ & Routine cultures' \\
\hline Morphology & $\checkmark$ & $\checkmark$ & $\checkmark$ & $\checkmark$ \\
\hline Viability & $\checkmark$ & $\checkmark$ & $V$ & $V^{a}$ \\
\hline Identity & $\checkmark$ & $\checkmark$ & $\checkmark$ & \\
\hline Doubling time ${ }^{b}$ & $\checkmark$ & $\checkmark$ & $\checkmark$ & $\checkmark$ \\
\hline Mycoplasma & $\checkmark$ & $V$ & $\checkmark$ & $(\sqrt[V]{ })^{\mathrm{c}}$ \\
\hline Viruses & $\begin{array}{l}\text { (donor only or historical } \\
\text { cell line testing) }\end{array}$ & & $\mathcal{V}_{\text {(master cell bank) }}$ & \\
\hline Bacteria and fungi & & & $\checkmark$ & $\nu^{d}$ \\
\hline Function/phenotype & & $\checkmark$ & $\checkmark$ & $V^{\mathrm{e}}$ \\
\hline Genetic stability & & $V^{f}$ & $\mathcal{V}_{\text {(master cell bank) }}$ & $V^{g}$ \\
\hline Absence of reprogramming vectors ${ }^{h}$ & & $V^{h}$ & $V^{\mathrm{h}}$ & \\
\hline Genetic lesion & 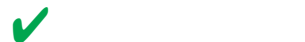 & $V$ & $\sqrt{2}$ & \\
\hline
\end{tabular}

a Viability testing at passage will ensure consistent seeding of fresh cultures and assays for more reliable maintenance of stock cultures.

${ }^{b}$ For diploid cultures subcultured at a 1:2 ratio, passage number is roughly equal to the number of population doublings (or population doubling level) since the culture was started. ${ }^{c}$ Many laboratories screen all cultures in routine use periodically to detect the introduction of contaminated cells. ${ }^{d}$ Sterility testing may be desirable for long-term cultures. A replicate set of flasks may be maintained as backup in case of contamination. ${ }^{e}$ Assessed by the correct performance of reference/control items. ${ }^{f}$ May be required for certain cell cultures. 9 May need to be established on a case-by-case basis. ${ }^{\mathrm{h}}$ induced pluripotent stem cells (iPSCs). ${ }^{\mathrm{i}}$ Original source of new cells arriving in laboratory. j Token stock refers to a stock prepared to guard against future loss (e.g., to enable recovery of the culture before formal master and working cell banks are established). It may also be used for panels of pre-master cell banks, where a large number of clones are produced and the final selection of the best performing clone is yet to be made, e.g., iPSC clones, recombinant cell lines. ${ }^{k}$ Cell banks refer to either master or working cell banks and pre-master stocks of cell clones may be treated as token stocks ${ }^{j}$ and subjected to more limited QC on a case-bycase basis. ' Refers to cells maintained in culture for routine use in the laboratory.

inoculation of microbiological culture media, which may need to be specialized for certain organisms like mycoplasma. Molecular methods, including qPCR, can provide sensitive and rapid methods for detection of all mycoplasma species and all bacteria by detection of conserved sequences in ribosomal RNA. Viral contamination screening may be more difficult to establish due to the high complexity and cost of performing tests for general viral contamination (e.g., electron microscopy, animal inoculation, and cell culture inoculation) and the potentially large number of viruses involved. However, screening for serious human bloodborne pathogens may be available for tissue donors, and regular microscopic observation may reveal viral cytopathic effects. Molecular screening by multi-virus PCR panels and next-generation sequencing methods could provide useful tools covering significant numbers of viruses (and are easily accessible via commercial service providers), but also require careful validation and control if used as primary safety tests.

During routine handling and maintenance, it is important to monitor characteristics such as viability, morphology, and absence of contamination. Sub-culturing details, including cell number and viability, subculture interval, seeding density, harvested cell numbers, and passage number should be recorded and checked against pre-defined GAC, such as PDL and passage num- ber. To mitigate against genetic and phenotypic stability in cases where such stability metrics are unknown, workers should strive to keep PDLs/passage numbers to the minimum required for the work and reduce risk from environmental contaminants.

For all cell and tissue culture harvesting stages, it is important to document viable cell numbers (see Principle 1) in order to permit cell numbers to be adjusted (e.g., to set appropriate cell concentrations for cryopreservation, for calculation of seeding densities, PDLs, and population doubling times).

The selection of a viability method should be based on the nature of the cell culture. Various methods are available for different cell types, and it is important to recognize that each type of technique measures different aspects of cell physiology, growth, and function (for a detailed discussion on viability and functionality tests representing a multi-center consensus, see Stacey et al., 2016a).

It is also commonly recognized that there is value in measuring culture "age" by calculating PDL whilst still recording passage number. This can be especially useful for cultures where (1) growth may vary significantly between donors, cell preparations, and different culture conditions, (2) to correlate directly PDL number with replicative senescence in finite cell lines and important phenotypic characteristics (e.g., reduction in telomerase activity, loss of functionality) in passaged primary cells and tissue-specific progenitor/ 
Tab. 2: Assessment of the quality of reagents used in cell and tissue culture

\begin{tabular}{|c|c|c|c|}
\hline \multirow[t]{2}{*}{ Reagent } & \multirow[t]{2}{*}{ Parameter } & \multicolumn{2}{|c|}{ Primary quality assessor } \\
\hline & & Supplier & End user \\
\hline \multirow[t]{3}{*}{ Serum } & Sterility and endotoxin testing ${ }^{a}$ & + & \\
\hline & Physical and biochemical analysis & + & \\
\hline & $\begin{array}{l}\text { Functional testing, such as plating efficiency and } \\
\text { growth promotion }{ }^{\text {b }} \text { and desired cell functionality }\end{array}$ & + (general) & + (specific) \\
\hline \multirow{3}{*}{$\begin{array}{l}\text { Basal medium, complete medium } \\
\text { (such as serum-free medium), additives } \\
\text { (e.g., non-essential amino acids, } \\
\text { growth factors) }\end{array}$} & Sterility and endotoxin testing & + & c \\
\hline & Physical and biochemical analysis & + & \\
\hline & $\begin{array}{l}\text { Functional testing to assure growth promotion }{ }^{b} \text { and } \\
\text { desired cell functionality }\end{array}$ & + (general) & + (specific) \\
\hline \multirow{3}{*}{$\begin{array}{l}\text { Detachment solution (e.g., trypsin/ } \\
\text { EDTA, collagenase, accutase) }\end{array}$} & Sterility testing $^{a}$ & + & \\
\hline & Physical and biochemical analysis & + & \\
\hline & $\begin{array}{l}\text { Functional testing to assure capacity to efficiently } \\
\text { detach cells without toxicity }\end{array}$ & + & c \\
\hline \multirow{3}{*}{$\begin{array}{l}\text { Surface coating for cell attachment } \\
\text { (e.g., fibronectin, laminin) }\end{array}$} & Sterility & + & \\
\hline & Physical and biochemical analysis & + & \\
\hline & $\begin{array}{l}\text { Functional testing to assure growth promotion } \\
\text { and desired cell functionality }\end{array}$ & + & c \\
\hline
\end{tabular}

${ }^{a}$ animal products should also be screened for virus testing such as bovine virus in bovine serum and porcine viruses for trypsin; ${ }^{b}$ growth rate and population doubling times; ${ }^{\mathrm{C}}$ some laboratories may elect to perform such testing

stem cells such as mesenchymal stromal cells, (3) to correlate PDL numbers directly with genomic instability (e.g., reduced chromosome length, mutation), and (4) to use PDL in GAC for the new cell preparations to compare and analyze across different studies.

Where primary cell cultures and tissues are used, variation in properties between individual donors and any evidence of microbial contamination (such as donor screening and microscopic observation) are important considerations. Each new batch of cells should be qualified or controlled for key aspects of functionality as GAC (Meza-Zepeda et al., 2008). Such assays may include morphology, histochemistry, cell markers, specific tissue function, and cell-cell/matrix interactions (Stacey and Hartung, 2006). For tissues, the selection of GAC (see 2.3) will be constrained by the size of test samples (although their culture media, storage solutions, or washes may be used for certain testing, such as microbial contamination). However, for primary cell cultures that are cryopreserved as banks of cells aliquoted in vials, a similar QC approach can be used as recommended for banks of continuous cell lines (Tab. 1).

\subsubsection{Plastics and glassware}

All cell culture devices making contact with cells (including flasks, cryovials, culture dishes, culture slides, tubes, cell scrapers, bioreactors, microphysiological systems, microfluidics, etc.) should be quality-controlled for cell culture compatibility (i.e., adherence characteristics and toxicity/biocompatibility) and sterility. Quality checks should include confirmation of suitable sterilization for glassware, and for plasticware this should be done by a defined and validated gamma-irradiation process. A review of the documentation provided by suppliers should include quality control checks to assure that relevant QC have been carried out (e.g., proof of sterility, cell culture testing, biocompatibility) and to ensure that each product meets the specific laboratory requirements for technical suitability and traceability (e.g., correct adhesion properties, expiry dates, batch numbers). Key documentation will usually include general product information and Certificates of Analysis for each batch produced, which should be kept for future reference. For biological surface coatings intended to support cell culture, the method of preparation will also need to be known to check that any necessary virological testing has been performed by the manufacturer. Synthetic nanofiber materials avoid the need to check such additional issues.

Any reused working materials should be checked for appropriate cleaning and sterilization, or if disinfection has been performed (see Principle 1).

\subsubsection{Growth media and culture additives}

Key factors needing to be addressed in QC of cell culture media and additives are sterility and biological activity, as outlined in Table 2. Most culture materials are obtained commercially, and suppliers should be expected to operate according to standards appropriate for cell culture products to provide the relevant QC documentation as described for glass and plasticware (see 2.1). Additional documentation will need to be checked regarding testing for biological activity and expiry date. Reagents that may be prone to significant variability or stability issues should be identi- 
Tab. 3: Examples of equipment quality parameters to be monitored

\begin{tabular}{|l|l|}
\hline Equipment & Parameter(s) \\
\hline Incubator & Humidity, temperature, $\% \mathrm{CO}_{2}$, presence or absence of significant vibration \\
\hline Refrigerators & Temperature \\
\hline Biological safety cabinet (BSC) class II & Flow rate, HEPA filter efficiency, particle count, air barrier test, UV lamp \\
\hline Cryostorage & Temperature, liquid nitrogen levels \\
\hline Autoclaves & Temperature, pressure, cycle time \\
\hline
\end{tabular}

fied, and the need for pre-use QC considered, such as growth promotion studies and plating or cloning efficiency assays. For further details on the use of chemically defined media, see Section 4.3.3 of GIVIMP (OECD, 2018) and the serum-free website ${ }^{2}$.

For cell culture work performed to generate formal quality standards for diagnostic assays (e.g., GLP, ISO $13485^{8}$ ), early method development (OECD, 2018), or supply of cells for medical use (e.g., GMP manufacture, clinical trials, medical devices), further quality checks may be required where cell culture still uses animal-derived materials. This will include copies of Certificates of Origin, a record of relevant product bacterial and virus testing (e.g., mycoplasma and bovine viral diarrhea virus testing for bovine serum, mycoplasma and porcine viruses for porcine trypsin), evidence for very detailed disinfection records (such as irradiation dose), and traceability back to animal husbandry procedures.

Today, large-scale production of primary mammalian cells is crucial to the success of cell therapy and tissue engineering for medical applications, as well as to biopharmaceutical production, but even more so for upcoming biotechnological solutions. Production methods should be sustainable and, therefore, cannot continue to rely on serum or other animal-derived materials that are non-replicative and of limited supply. The use of serum is equally undesirable from animal welfare and regulatory perspectives (OECD, 2018). Still, bovine-derived serum products are being used, although strong societal pressure is discouraging such uses. For bovine products, such as fetal or donor calf serum, only cattle under 30 months of age and from countries free of bovine transmissible spongiform encephalopathy (a self-replicating abnormal prion protein) should be used (for a list of countries with endemic disease see the OIE list ${ }^{9}$ ). In some cases, if risk of contamination has not been adequately mitigated by the manufacturer's testing, additional testing of the reagent/additive for potential viral agents may also be required.

\subsubsection{Equipment}

Quality checks on equipment are necessary to ensure correct function, maintenance of acceptable calibration as equipment read-out might be prone to drift in accuracy, and general preventative main- tenance checks. Equipment may fail to function properly due to ageing, damage, excessive use, misuse, or lack of regular maintenance. For this reason, it is recommended that calibration/verification, maintenance, and cleaning are performed by the laboratory on a regular basis and records are maintained (see Principle 3). In addition, certain critical operating parameters should be checked before each use (see Tab. 3).

Any working materials that are re-used and come into direct contact with the cells should be cleaned and sterilized by a qualified method and handled aseptically to avoid the need for sterility testing. Suitable sterilization methods for this purpose include gamma-irradiation and autoclaving by steam sterilization. For materials where these approaches are not suitable, a range of other methods exist, such as treatment with ozone, hydrogen peroxide, and ethylene oxide, but these need to be selectively used, as some are not suitable for materials sensitive to heat and/or moisture and may be affected by disinfection residues.

Reliability and reproducibility of micropipette measurement can be critical to obtaining good-quality data. However, such pipettes may become less reliable due to wear and tear, being misused, or suffering sharp impacts. Therefore, it is important that they are regularly maintained, cleaned, lubricated (where applicable), and periodically recalibrated to ensure accuracy and precision over their complete lifecycle (see ISO $8655^{10}$ ). As for all critical equipment (where feasible), calibration should be traceable to certified standards, such as use of certified weights to calibrate a microbalance. Repairs and maintenance records can also be monitored and reviewed over time to help identify trends or root causes of suboptimal data.

In order to facilitate the establishment of QC based on standardized GAC, recognized national and ISO standards available for key equipment should be used, e.g., calibration of piston pipettes (ISO 865510), autoclave operation (ISO 17655'11), and Class II BSC performance (EIN 12469 ${ }^{12}$ ).

The use of computerized systems for monitoring and generation of electronic data is now integral in most laboratories and, therefore, controls should be put in place to ensure data integrity over time according to valid project guidance documents or other official rules/legislation for data storage.

\footnotetext{
8 https://www.iso.org/standard/59752.html (accessed December 7, 2021)

9 https://www.oie.int/en/animal-health-in-the-world/official-disease-status/bse/list-of-bse-risk-status/ (accessed December 7, 2021)

10 https://www.pipettes.com/calibration-services/quality-program/iso-8655 (accessed December 7, 2021)

$11 \mathrm{https://www.iso.org/standard/37453.html} \mathrm{(accessed} \mathrm{December} \mathrm{7,} \mathrm{2021)}$

12 https://standards.nsf.org/apps/group_public/download.php/1840/EN\%2012469\%202000.pdf (accessed December 7, 2021)
} 
QC for devices used for complex bioreactor, microphysiological, and organ-on-a chip systems is, in many cases, at a relatively early stage of development, although some issues that need to be controlled may include diffusion, shear, mass action effects, and manufacturing controls on device components. For further details on control of laboratory equipment, see GIVIMP (OECD, 2018).

\subsubsection{Laboratory environment}

A major requirement of a cell culture laboratory is maintaining an aseptic work area restricted to cell culture work and media preparation. Although a separate tissue culture room is preferred, a designated cell culture area within a larger laboratory can be used for aseptic handling, incubation, and storage of cell cultures, reagents, and media. It is also important to have some way of isolating cultures new to the laboratory (e.g., separate laboratory, separate incubator and media storage, or handling only at end of a working day with before and after thorough disinfection). This will mean that they are tested for microbial contamination before they are used in general laboratory work. Due to the various sources of contamination in a laboratory (e.g., doorways, ventilation from the open air, packaging, fridges, sinks, staff), it is good practice to establish and monitor effective laboratory cleaning regimes to avoid build-up of contamination. Closed cell handling systems provide a physical barrier between open cell cultures and these sources of contamination. For certain applications, it may be required that laboratory air quality is monitored (e.g., particle counting, settle-plates, finger dab plates).

The simplest and most economical way to provide aseptic working conditions is to use a BSC Class II for cell culture and, if available, a horizontal or vertical laminar airflow cabinet for media preparation and handling of sterile materials (it is important to note that horizontal laminar air flow cabinets provide a steady laminar flow of filtered air toward the operator and should not be used for cell cultures or infectious material). The HEPA-filtered air provided in such cabinets is important to maintain a clean environment within the cabinet, where cell culture work and/or media preparations would otherwise be directly exposed to the open laboratory air (e.g., cell seeding, passage, harvest, and opening sterile medium containers). Air quality in such situations is typically established according to ISO $14644-1^{13}$ and other national standards as applicable for the work. Class II BSC should meet specific standards (e.g., EN12469:2000, NSF/ANSI 49-2016/ BS5726) or national standards, which must be maintained while cell culture operations are carried out. These standards include checking the efficiency of HEPA filters, air flow rate from the cabinet, and operator protection factor for BSC Class II cabinets. Horizontal laminar flow cabinets should have a defined ISO standard air quality and are typically used for media preparation. They are designed to protect the work but provide no operator protection and should never be used for cell cultures or hazardous materials. Working in a BSC Class II with poor aseptic technique will decrease the cabinet's protective effect for work and worker, and examples of precautions to ensure the correct and safe use of a Class II BSC are given in Appendix $6^{1}$.

Cell culture contaminants may include reagent impurities (in media, sera, water, and endotoxins), plasticizers (in plasticware), volatiles (e.g., formaldehyde from paper towels, organic volatiles in paints), detergents, and micro-organisms.

Certain kinds of laboratory activities, such as work with infectious organisms, biological toxins, flammable liquids, radiochemicals, nanomaterials, etc., may require consideration of specialist environmental controls (See Principle 5).

\subsubsection{Data management}

For the purposes of scientific good practice and protection of intellectual property, some laboratories may require documented review and authorization of research data, including personal laboratory books. For human cell lines, special measures should be taken to safeguard the donor's personal information, which may include patient records or genetic sequencing data. Donor data should be pseudonymized or anonymized to hinder donor re-identification. Sample labelling should not include any personal information that could be used to identify the person. At a technical level, the quality of data storage is important, and for certain applications data storage systems will require validation for integrity, stability, and security, including regularly scheduled off-site data backups and operating system updates and software patches, to ensure that all computer software is up-to-date. Data import and transfer into software are also important and often overlooked problems. When data are transferred between different software or versions (e.g., spreadsheet files imported into a database or handwritten data transferred into electronic format), the transferred data should be checked for completeness, consistency, and accuracy. For example, when importing text files of transcriptome data into a spreadsheet program, gene symbols may be wrongly imported as dates (Zeeberg, 2004; Ziemann, 2016), which can lead to erroneous conclusions about the affected genes. Before transferring data between different software packages, the compatibility of the software packages should be tested (e.g., compatibility of data/number formats). These issues are of special concern where data are exchanged between countries where different formats (for example, decimal separators) may be in use. This aspect of laboratory work is also covered in detail in Section 10.1 of GIVIMP (OECD, 2018).

\subsection{GCCP acceptance criteria (GAC) for cell culture status and composition}

\subsubsection{Definition and rationale}

Introduction of increasingly prescriptive procedures or SOPs does not solve the problem of defining the suitability of cells for a given experimental purpose. The reason is that there are too many parameters that would fully define the state of cell cultures. An alternative approach is the definition of quantitative GAC that define the minimally acceptable state/parameters of a

13 https://www.iso.org/standard/53394.html (accessed December 7, 2021) 
cell culture. The definition of GAC includes guidance on how this can be measured and what variation from the optimum is acceptable. In addition, certain cell systems, such as differentiated PSC, may develop to the desired state through a characteristic differentiation trajectory. Where this is complex and prolonged, GAC may need to be defined for such a trajectory or intermediate stages of differentiation. This approach is especially important for the increasing diversity and complexity of cell types and technologies involved in cell culture systems and regulatory needs, which bring new demands for quantitative quality assurance (QA). In parallel with regulatory demands, academic research is increasingly committed to rules that ensure reproducibility of research data. In this context, the necessary additional element to ensure data quality is that GAC are incorporated with optimal and acceptable ranges and limits (see Section 2.2.2) in all SOPs. This part of the GCCP principles describes how the desired cell culture states can be defined, quantified, and assigned limits of acceptable variation. It does not attempt to comment on principles of best practice for assay development, which is dealt with in GIVIMP (OECD, 2018). Please note that GAC has a different meaning from GIVIMP acceptance criteria.

Nevertheless, GAC may be required in the stages of generation of a cell culture system in the scope of GCCP, and these include: - establishing a new cell culture in the laboratory

- recovery of cells from a cryopreserved state

- seeding cell culture flasks or other culture devices

- in-process monitoring for stability or predetermined profiles of temporal culture development, such as cell differentiation

- final expanded cell culture system to be used in an assay

The differentiation of cells may be formally included as part of the intended final use, such as an assay or product manufacture procedure, and may only be considered at that stage. Clearly, the quality of output from each of these stages can affect subsequent quality, such as the thawing of cells (stage 2) for expansion (stage 3). In this example, it would be important to investigate and understand the root causes and features of failed batches of cells in order to improve the GAC and overall efficiency of cell supply. Typically, this may be achieved by operator training, better standardization of thawing procedure and culture temperatures (Shimoni et al., 2018), better control of freezing and storage procedure, etc.

\subsubsection{How to define GCCP acceptance criteria}

\subsubsection{Background and examples}

GAC are clearly important where a parameter has applicable quantitative measurement; where this is not the case, it may be necessary to develop a measurement method or to investigate and validate alternative measurable parameters. An experienced operator may intuitively assess cell culture status based on a number of key parameters, such as morphology, size, confluency, general appearance, and other parameters like passage number, discarding cultures they regard as unsuitable. However, it is important to attempt to formalize such intuitive evaluations in the form of transparent, repeatable, and quantifiable GAC. In this way, reproducibility, robustness, and reliability of data can be enhanced by better definition of the culture state and allow the sometimes-significant variations between operators to be reduced. Examples of fundamental types of GAC are the seeding efficiency, plating efficiency, and proliferation rate of the cell line in use. Such parameters may change with increasing population doublings (Vracko et al., 1983) or use of different cell culture conditions (Chan et al., 2008). The specific sets of criteria are likely to vary for different cell cultures and may also need to be developed for different applications of those cultures.

\subsubsection{Setting GCCP acceptance criteria}

For GAC, each individual acceptance criterion will have three main elements:

- the parameter to be assessed

- the method of quantification

- the acceptable range

\section{i) Selection of appropriate parameters}

Setting GAC for a particular cell preparation begins with identifying the set of informative biological parameters that together describe the optimal state of the culture for its intended use. These commonly relate to viability, growth and proliferation, cell identity, cell subpopulations, stability on passage, functionality, and microbial contamination. Approaches to development of GAC in these specifications are given in Appendix $3^{1}$. Typically, desirable parameters (inclusion parameters) are used, such as expression of a required marker, morphological feature (e.g., bile canaliculi, neurite growth), or functionality (e.g., antibody secretion, electrical action potential). However, parameters may also be selected based on knowledge of features that can make the final cell culture unsuitable for use (exclusion parameters), such as contamination (e.g., bacteria, such as mycoplasma), abnormal morphology (e.g., vacuolation, syncytia), or appearance of inappropriate cells (such as overgrowth of primary epithelial cells by fibroblasts or appearance of spontaneously differentiated cells in PSC cultures). Use of parameters based on cell surface markers or mRNA expression do not necessarily correlate directly with culture functionality, but can provide valuable information, given that markers of biological functions may be difficult to standardize and measure reliably.

Ideally, the parameters relating to each of the GCCP acceptance criteria should be fully quantifiable, although semi-quantitative or qualitative determinations may still be valuable.

\section{ii) Quantification and range setting}

Once parameters have been selected, the quantification method and optimal value - or tolerance around that value - need to be clearly defined for each culture. This will also require a good understanding of the test method characteristics (precision, accuracy, specificity, reproducibility, etc.) and establishment of suitable control tests and reference materials to give assurance of the correct performance of the detection. Limit values need to be clearly defined. It is important to note that at the early stages of adopting new methodology, these characteristics may be unknown or poorly developed. However, they should be considered during early development work to enable eventual assurance of good-quality data. 
Care is needed where semi-quantified values are used, including morphological (such as the shape of cells or descriptions of colonies) or functional parameters where biometric approaches have yet to be validated or developed. In such cases, only staff fully trained and experienced in the specific cell system should be involved in scoring, and expert consensus on the related GAC should be sought.

It is important to note that other aspects of quality testing methods will need to be considered, such as detection inhibitors, response linearity, sensitivity, repeatability, etc., but are beyond the scope of this good practice document.

iii) Maintenance and development of GCCP acceptance criteria As already discussed in 2.1, for some GAC, no validated assays may exist or they are very challenging to establish, as in the case of some functional assays. In such cases, workers need to keep under review any relevant new scientific developments and be prepared to validate and implement new quantifiable assays where scientific consensus has been reached. See GIVIMP Chapter 8 for more information on acceptance criteria for test methods (OECD, 2018).

Multi-laboratory coordination involving exchange of standardized materials (sometimes called "ring trials" or "collaborative studies," depending on the field) can reveal hitherto unrecognized variability and the need for new GAC and additional quality testing (Volpato et al., 2018; Kleensang et al., 2016). Engagement in such studies, where relevant, can contribute to maintaining ongoing improvement in QC, standardization, and compliance with professional standards.

\subsubsection{Spatial and structural aspects of cell culture systems}

GAC for traditional 2D cell cultures have been established for many years. However, it is becoming clear that hardly any cell culture is truly 2-dimensional and that also so-called monocultures contain a variety of different cell states/shapes/sizes/functionalities. Our increasing understanding of the variability and complexity of cell culture systems means that we may need to revisit and improve long-established approaches to QC and to the definition of GAC.

The issue of complexity is even more pronounced for 3-dimensional culture systems involving combinations of factors, including new culture environments and conditions, phenotypic development, migration, matrix production, etc. The setting of GAC requires careful considerations of the culture use. Possibly, new parameters and endpoints need to be established.

Components of the physical engineering hardware, such as impellers, detectors, baffles, culture surfaces/treatments, etc. will also need key parameters set for their function, including porosity, surface topography, biocompatibility testing, assessment of potential leachates, and physical impact on cell viability by high energy aspects (e.g., impeller speed, frothing, sonic filters). Construction of cell systems by bioprinting methods will also need careful analysis with GAC for the make-up of the construction material (including cells, surface matrix, growth factors, excipients/fillers, and other components) and to assess cell loss in manufacturing and function in the final construct.

Another important and very challenging issue is the assessment of in vivo transplanted cells or constructs. Here, the size, functionality, structural composition, and vascularization may all be important in comparing and standardizing between experimental data sets. The potential solutions are highly diverse and may be bespoke to each system. For a review of current techniques, see Scarfe et al. (2017).

\subsubsection{Matrix}

As already discussed (Principles 1 and 2.2), biological matrices used to simulate the extracellular matrix of a native tissue are prone to variability and other quality problems, although a number of these are eliminated or reduced by the use of synthetic matrices (such as hydrogels). Nevertheless, there are few instances where GAC have been documented for the surface matrices, primarily due to technical difficulties of defining and quantifying the state of the model extracellular matrix (ECM) (composition, structural consistency, porosity, molecular integrity, etc.). It is important to understand the chemical composition and molecular structure of each ECM model and the method of manufacture. Identification of critical elements may enable development of GAC based on meeting a specification for source materials and manufacturing process. These GAC may need to be qualified by the manufacturer, as they may be beyond the knowledge, skills, and resources of the average cell culture facility. This is problematic, e.g., upon change of manufacturer or in case of very complex ECM. An alternative approach that is commonly taken in this situation is to define the GAC based on the performance of the cell cultures grown on them. This requires: (1) that a reference ECM is defined that is considered as gold standard for performance, and (2) that a suitable set of endpoints of cell culture performance is defined that covers the later experimental uses. For instance, it will not be sufficient in most cases to define GAC only based on culture viability and morphology. As a second level, a functional parameter will be important (e.g., cell migration, signal transduction or a metabolic feature). In many cases, even a third level may be required, e.g., the response of the second level parameter to positive and negative control agents).

In some cases, direct measurements on ECM materials may be important (e.g., the content of certain growth factors or of fibrinogen in Matrigel ${ }^{\circledR}$ lots or alternative supplier products). This may help the identification of drift in composition and structure on in-batch differences. It is also important to monitor scientific developments so that improved GAC can be introduced or new non-animal-derived ECM materials can be introduced (Nesterenko et al., 2020).

\subsubsection{Composite cultures}

The various types of complex cell culture systems described in Principle 1 include a range of models using composites of multiple cell types that may require specific additional GAC, depending on the types and ratios of cells involved, their nature, physical structure, and the kinds of additional materials used, including artificial or natural surfaces or constructs. These types of culture 
systems may need GAC setting, such as cell ratios, structural definition, or combined functionality and morphology of the overall construct. In addition, the purity of the original preparations is likely to be a key GCCP acceptance criterion (as discussed above - see Section 2.3.1) that may include expansion of unwanted cells (e.g., fibroblast expansion from tissue explants, side-populations of differentiating PSCs, composition of self-organizing organoid systems, cell ratios in co-cultures). Examples of considerations for development of GAC for some key composite cell systems are described in Appendix $7^{1}$. Such systems may also require temporal monitoring of certain parameters related to the expected profile of developmental progression of the culture to its desired mature endpoint (see Principle 1 and Section 2.2).

\subsubsection{Cellular engineering}

Cell engineering in the context of GCCP includes the highly diverse interventions outlined in Principle 1. Numerous examples (notably hybridomas) are now treated for QC purposes as if they were "standard" continuous cell lines, but some may have been altered in a way that requires new and bespoke GAC (see also Appendix 2 and $3^{1}$ ). The complexity of tools used to create these new engineering techniques may also require GAC to be set up for the molecular tools used (e.g., plasmids, guide RNAs, enzyme preparations) as well as to check that the appropriate molecular and cellular changes have been affected, undesirable changes are absent, and unrequired elements are eliminated from the cell culture (e.g., episomal reprogramming vectors). Two general points should be considered for cell engineering: (i) each new technology will require re-consideration of GAC, as it is being introduced to cell cultures and (ii) a robust set of GAC, once established, helps introduce such new technologies by assuring that the originally defined and desired cell culture quality is not altered by the new approach.

\subsubsection{Gene expression regulation using DNA vectors, RNAi expression inhibition, and gene editing}

Given the complex and potentially unstable nature of genetically modified cells (discussed in Principle 1), appropriate acceptance controls relating to the technology used need to be established for a number of control points, which may include:

a) the derivation of the modified cell line

b) the initial characterization of the cell line (i.e., upon generation or upon introduction to the laboratory from other sources)

c) the creation of cell banks

d) the ongoing monitoring of cultures routinely maintained for experimental purposes

Concerning (c), the stability characteristics of the genetic modification and any constructs used has to be considered. It will be important to identify any additional parameters (e.g., Stepanenko and Heng, 2017) that may need consideration in a GAC setting based on an understanding of whether and how the role of the constructs may be affected by cell culture conditions or further interventions (e.g., additional genetic modification, cell differentiation protocols). As examples, constitutive CMV-based promoters drastically change activity during differentiation of LUHMES cells (Scholz et al., 2018; Schildknecht et al., 2013), and tissue-specific promoters may behave unexpectedly upon differentiation of murine ESCs.

In the case of the latter control point (d), it may also be necessary to use experience gained in the development of the cell line to identify and set GAC to be used for periodic re-testing and after differentiation into the final cell type used in experimental work.

\subsubsection{Cell fusion}

As described in Principle 1, cell fusion is a highly complex process that may be achieved in vitro by a broad range of mechanisms. Thus, the impact of the method of fusion, added to the complexities arising from the combination of cells and genes/genomes, may make it difficult to anticipate GAC specific to each technique and its application. However, workers should investigate the literature and seek published scientific consensus to establish suitable parameters for the development of GAC in the particular cell fusion culture of interest.

\subsubsection{Effects of analytical instrumentation and methodology on cells}

\subsubsection{Variation of culture conditions required by analytical endpoints}

Cell characterizations, including the definition and application of GAC, often refer to a given culture format or a single experimental situation. In such cases, it is important to consider whether the cell characterization also applies to the setting used for experiments. Well-known examples include the study of coverslip cultures in flow chambers, microelectrode arrays (MEAs), or special vessels to measure oxygen consumption (e.g., SeaHorse dishes). It is also increasingly common to have diverse experimental conditions in which cells are exposed to light, modified atmospheric or other physical conditions that may alter the performance of the cultures and, therefore, need to form part of the GAC considerations to assure they are suitable for the intended analytical platform. It may be assumed that such platforms do not affect the cells, but only the measurement of GAC can give an indication whether the cells retain the required range of properties measured during characterization in more standard cell preparation culture systems. It is important to ensure cell analysis equipment is maintained at environmental conditions suitable for its reliable use and that analytical probes are stored appropriately, e.g., correct pH buffer. Monitoring GAC can guide definition of optimal assay conditions for each cell or tissue model.

\subsubsection{Effects of the analytical method on cell cultures}

An often-underappreciated problem experienced in cell culture quality is the effect of analytical methods on cells. This can result in drastically altered cultures and also in variation of test results due to changes in the cell culture response. This may not be accounted for entirely by generic sets of GAC, and it requires the setting of control parameters to establish potential changing influences on the cultures.

An example is the sorting of cell populations by fluorescence-activated cell sorting (FACS) or by antibody-mediated magnetic sorting. Such methods can affect the cells, for exam- 
ple, by shear forces or internalization of magnetic beads. Another important group of examples refers to the loading of cells with fluorescent indicators. They may alter calcium buffering in cells, contribute to phototoxicity not seen otherwise, or have other side-effects that require control. Basically, all live-cell imaging methods (even though they are considered to be non-invasive) may involve stimuli with consequences that cannot always be anticipated and that may require control of the cell populations under defined assay conditions. In particular, methods involving transient transfections (e.g., electroporation, lipofection, calcium phosphate precipitation) of reporters used to establish analytical endpoints are known to potentially have significant effects on cell functions and viability. Moreover, such effects may show large variations between experiments.

\subsubsection{Non-mammalian cells and model organisms}

Whilst GCCP 2.0 is focused on mammalian cells, the general principles of GAC setting are applicable to non-mammalian cells. However, there are some specialized aspects, and a few examples are listed below as possible alerts.

A high level of specialist knowledge may be required for setting GAC for certain non-mammalian cells, such as Xenopus oocytes (frequently used for electrophysiology and cell cycle research). Cell cultures and cell lines from other species (e.g., avian, fish, amphibian, and insect) are frequently used in research and development, and even in manufacture (such as insect cells for protein expression). Prokaryotic organisms (e.g., yeast, bacteria) and plant cell and tissue cultures are also commonly used in research and industry. Other more complex animal cell systems are also used as cell culture systems, including fertile hen's eggs (such as the HET-CAM assay), zebrafish embryos cultured and measured in cell culture plates (see the FET assay according to OECD TG 236), and C. elegans or planaria. It is particularly important to note that the variation, drift, and uncertainty in these systems are unlikely to be less important than for mammalian cells and will require special scientific evaluation to ensure that suitable GAC are implemented beyond those referred to in GCCP 2.0.

\section{Principle 3: Documentation and reporting of the information necessary to track the materials and methods used, to permit the replication of the work, and to enable the target audience to understand and evaluate the work}

In cell and tissue culture, as in any scientific work, clear documentation of the in vitro systems used and an exact recording of the experimental data obtained are important prerequisites for precise reporting of cell culture systems and in vitro results. Accurate records of cell type, origin of the cells, their quality control, the materials used, and the culture techniques performed are essential for confidence in experimental data. Furthermore, thorough documentation and recording improve the transparency and efficiency of scientific research, can be used to improve reproducibility, and enable work to be repeated (Baker, 2016a,b; Munafo et al., 2017). Such records should be clear and traceable.
Specific challenges of in vitro culture systems are the inherent variation of the cultured cells, genetic instability, and/or phenotypic drift of the culture, ageing, and cell senescence in culture due to prolonged passaging, unrecognized viral and/or mycoplasma infections, cross-contamination, or mislabeling of cultures (Principle 1). Therefore, a precise record of the cells, their origin, authentication, and characterization, along with exact documentation of the culture techniques and the cell culture materials used, is recommended.

The term "recording" means to take careful notes of the cell culture work and to document the experimental conditions as they occur, as well as the protocols and the experimental data as they are generated. "Reporting" is the process by which recorded data are summarized in a final report, a publication, or an oral presentation. Recording and reporting should be in accordance with good research practice (Geraghty et al., 2014). Where laboratories are performing to certain quality standards (e.g., GLP, GMP), it will also have to comply with any additional requirements, including the establishment of formal procedures for document retrieval and review and for resolving any questions or disputes that may arise.

The documentation for all cell and tissue culture work should be retrievable, and may include:

- the objective of the work

- the rationale for the choice of procedures and materials used

- the origin, supplier, and characterization of the cells and/or tissues

- the materials and equipment used, including maintenance records, expiry dates, etc.

- cell and tissue preservation and storage procedures

- the laboratory records, including monitoring, results, raw data, and quality control records

- the protocols and SOPs used, controls used, and any deviations from them

- deviations from normal condition

The exact level and kind of information stored may vary depending on the demands of the research or the quality standards adopted. More detailed information for those developing cell and tissue-based methods can be found in GIVIMP (OECD, 2018).

\subsection{Source, origin, and basic description of cultured cells}

A minimum set of information is essential when working with cells or tissues of animal or human origin, either primary cultures (Tab. 4) or continuous cell lines (Tab. 5). For the novel field of stem cell culture, either embryonic stem cells (ESCs), induced pluripotent stem cells (iPSCs), or tissue-specific progenitors or stem cells (such as mesenchymal stem or stromal cells (MSCs)), additional data sets are required for comprehensive documentation (Tab. 6) (Pamies et al., 2017, 2018).

When a cell line is established, it is important to avoid giving the cell line a previously used name in order to prevent confusion, especially when the lines are referred to in publications. Although there is no universally accepted naming convention for all cell lines, some fields, such as PSCs, have published standards to systematically create unique cell line identifiers (Kurtz 
Tab. 4: Proposed data set for primary cultures of animal or human origin

\begin{tabular}{|c|c|}
\hline Field & Contents \\
\hline Date and type of preparation & $\begin{array}{l}\text { Date of preparation } \\
\text { Type of primary culture (e.g., hepatocyte culture, renal epithelial culture, skin } \\
\text { fibroblasts, tumor cells, tissue-specific progenitor and stem cells (MSCs)) }\end{array}$ \\
\hline Origin of tissue & $\begin{array}{l}\text { Animal species/strain } \\
\text { For humans: ethnicity } \\
\text { Age and sex } \\
\text { Organ/tissue/biopsy } \\
\text { Donor live or deceased }\end{array}$ \\
\hline Pathology & $\begin{array}{l}\text { Site and type of tumor and possibly description of histology } \\
\text { Procedure of tissue excision }\end{array}$ \\
\hline Method of tissue dissociation and cell harvest & $\begin{array}{l}\text { Enzymatic dissociation: type, source, concentration of enzymes, duration of } \\
\text { incubation, and temperature } \\
\text { Mechanical dissection/disaggregation } \\
\text { Composition of dissociation media and transport media } \\
\text { Bibliographic reference of method (if available) }\end{array}$ \\
\hline Culture conditions and maintenance & $\begin{array}{l}\text { Initial seeding density and density assessment/harvest (cell count) } \\
\text { Culture medium volume, composition, and supplements } \\
\text { Specialty media } \\
\text { Incubation conditions (temperature, } \mathrm{pH}, \mathrm{CO}_{2} \text {, etc.) } \\
\text { Culture vessels, type of vessels, company: Pre-treatment or coating (e.g., culture } \\
\text { substrate) }\end{array}$ \\
\hline Hazard & $\begin{array}{l}\text { Biological risk assessment: } \\
\text { For animals: germ-free animals or infected with viruses, parasites, colony } \\
\text { screening, etc., } \\
\text { For humans: donor tissue (patient) tested for viral infection (HIV, hepatitis B + C), } \\
\text { any special features of the donor cohort }\end{array}$ \\
\hline Compliance with ethical and legal regulations & $\begin{array}{l}\text { For animals: } \\
\text { Evidence for compliance with national animal experiment and animal welfare } \\
\text { legislation, } \\
\text { Evidence for approval by local animal welfare committee } \\
\text { For humans: } \\
\text { Evidence of ethical approval (informed consent by the donor) and approval by } \\
\text { local ethics committee } \\
\text { Identification of ownership and patents } \\
\text { Terms of cell usage (conditions of consent or transfer agreement) and usage } \\
\text { of data obtained from the cells, which may identify a person (such as DNA } \\
\text { sequencing) }\end{array}$ \\
\hline
\end{tabular}

$\mathrm{a}$ if deceased, the cause of death and duration between death and cell/tissue collection and processing should be noted.

et al., 2018; Reid, 2017). In the absence of a community-accepted standard for cell line names, it is sensible to assign new cell lines a Reference Resource Identifier (RRID, maintained by Cellosaurus for vertebrate and invertebrate cell lines ${ }^{4}$ ), which should be used in all subsequent research outputs to uniquely link the line with its data (Bairoch, 2018). Researchers are of course free to use "working" cell line names, but each line should have a unique identifier attached to its dataset to disambiguate commonly used cell line names. In the case of cells for use in humans, very detailed traceability is needed to create a cell history file for regulatory review to assert suitability for clinical use (Andrews et al., 2015; Stacey et al., 2013). For human PSCs, the collection of the data outlined in Table 4-6 can be alleviated by registering the hPSC lines in hPSCreg ${ }^{3}$. 
Tab. 5: Proposed data set for animal and human cell lines

\begin{tabular}{|c|c|}
\hline Field & Contents \\
\hline Cell line name & $\begin{array}{l}\text { Designation (name) of cell line as listed in cell bank catalogues and used in the } \\
\text { literature, respectively }\end{array}$ \\
\hline Accession number & $\begin{array}{l}\text { Cell code } \\
\text { Cell bank catalogue number }\end{array}$ \\
\hline $\begin{array}{l}\text { Brief description of cell line, donor, or donated } \\
\text { tissue }\end{array}$ & $\begin{array}{l}\text { Species } \\
\text { Age and sex } \\
\text { Strain } \\
\text { Organ/tissue } \\
\text { Tumor } \\
\text { Diagnosed disease(s) or/and any known associated genetic variants } \\
\text { Transformed/transfected/immortalized } \\
\text { Clonal cell line } \\
\text { Passage number of cells received }\end{array}$ \\
\hline Morphology and growth characteristics & $\begin{array}{l}\text { Morphology (epithelial-, fibroblast-like) } \\
\text { Growth characteristics (monolayer, suspension) } \\
\text { Contact inhibition (yes/no) } \\
\text { Neoplastic properties (if tumorigenic) }\end{array}$ \\
\hline Specific properties (where appropriate) & $\begin{array}{l}\text { Metabolic properties (cell-specific features): } \\
\text { Cell products (e.g., enzyme release, monoclonal antibodies) } \\
\text { Expression of differentiated functions (metabolic pathways, transporters, } \\
\text { channels, receptors, signaling, surface antigens, etc.) } \\
\text { Viruses: } \\
\text { Test results } \\
\text { Susceptibility to viruses } \\
\text { Virus production and release }\end{array}$ \\
\hline Culture conditions & $\begin{array}{l}\text { Type of culture medium, medium composition, and volume } \\
\text { Specialty media } \\
\text { Incubation conditions (temperature, } \mathrm{pH}, \mathrm{CO}_{2} \text {, etc.) } \\
\text { Culture vessels, type of vessels, company: } \\
\text { Pretreatment } \\
\text { Coating material } \\
\text { Initial seeding density and density at assessment/harvest (cell count) }\end{array}$ \\
\hline Maintenance & $\begin{array}{l}\text { Subculture protocols (number of passages, dissociation agent, time, temperature, } \\
\text { seeding density, split ratio) } \\
\text { Feeding/refeeding cycles }\end{array}$ \\
\hline Characteristics & $\begin{array}{l}\text { Morphological appearance/phenotypic drift } \\
\text { Genotype/genotypic alterations compared to the donor } \\
\text { Ageing and senescence } \\
\text { Expression of products (see special properties) }\end{array}$ \\
\hline Quality control & $\begin{array}{l}\text { Viability } \\
\text { Mycoplasma testing } \\
\text { Bacteria and fungi testing } \\
\text { Viral testing } \\
\text { Agents associated with transmissible spongioform encephalopathy }\end{array}$ \\
\hline Identification and authentication & $\begin{array}{l}\text { Karyotype analysis (for animal cell lines) } \\
\text { Isoenzyme pattern (for animal cell lines) } \\
\text { DNA profiling (for human cell lines) } \\
\text { COX1 gene sequencing (all cell types) }\end{array}$ \\
\hline Source of cell line & $\begin{array}{l}\text { Source from which cell line was obtained: } \\
\text { purchased from biobank } \\
\text { received from other laboratory } \\
\text { thawed from master bank } \\
\text { Specific name used in the original publication and/or biobank reference }\end{array}$ \\
\hline Hazard & $\begin{array}{l}\text { Risk assessment for microbiological hazards } \\
\text { Hazard classification of the cell line }\end{array}$ \\
\hline Bibliographic references & $\begin{array}{l}\text { Reference paper, e.g., the original paper (if available) } \\
\text { Additional key references on the cell line }\end{array}$ \\
\hline
\end{tabular}


Tab. 6: Supplementary data set proposed for human and animal stem cell cultures (for key tests see, e.g., $\left.{ }^{3,14,15}\right)^{\mathrm{a}}$

\begin{tabular}{|c|c|}
\hline Field & Contents \\
\hline Type, source, and origin of stem cells & $\begin{array}{l}\text { Human or mouse embryonic stem cells (ESCs), including parthenogenetic } \\
\text { embryonic stem cells (pESC) and somatic cell nuclear transfer embryonic stem } \\
\text { cells (SCNT-ESC) } \\
\text { Adult tissue specific progenitor or stem cells (TSPSCs), including mesenchymal } \\
\text { stromal cells (MSCs) } \\
\text { Induced pluripotent stem cells (iPSCs) }\end{array}$ \\
\hline hPSCreg reference code & $\begin{array}{l}\text { A unique, standardized cell line nomenclature identifying the cell line, which is } \\
\text { automatically generated upon pluripotent stem cell line registration in hPSCreg } \\
\text { database }^{3}\end{array}$ \\
\hline ESCs & $\begin{array}{l}\text { Origin } \\
\text { Method of isolation/production e.g., blastocyst inner cell mass isolation, } \\
\text { parthenogenetic division, nuclear transfer to an oocyte } \\
\text { Description of any cloning procedures }\end{array}$ \\
\hline TSPSCs (MSCs) & $\begin{array}{l}\text { Tissue origin } \\
\text { Mode of isolation/production }\end{array}$ \\
\hline iPSCs & $\begin{array}{l}\text { Somatic cell origin (e.g., fibroblasts, keratinocytes, lymphocytes) } \\
\text { Reprogramming method: } \\
\text { a) viral: integrated, non-integrated } \\
\text { b) chemical } \\
\text { c) vector clearance / silencing status }\end{array}$ \\
\hline $\begin{array}{l}\text { Characterization of pluripotent, undifferentiated } \\
\text { state }\end{array}$ & $\begin{array}{l}\text { General performance of stem cell cultures } \\
\text { Undifferentiated growth characteristics } \\
\text { Expression of stem cell markers } \\
\text { Expression of stem cell self-renewal markers } \\
\text { Pluripotency assays, e.g., in vitro embryoid body formation, directed differentiation } \\
\text { in vitro to form cells representing the three germ layers, teratoma formation in } \\
\text { animals. For mouse only, germline complementation assays. } \\
\text { Epigenetic profile / epigenetic memorya }\end{array}$ \\
\hline Compliance with ethical and legal regulations & $\begin{array}{l}\text { For all human stem cell lines: } \\
\text { Compliance with legal regulations in terms of use of human embryos (for hESC } \\
\text { lines) and other human tissue (for iPSC lines and MSCs) } \\
\text { Ethical approval (informed consent by the donor) (NB these details are evaluated } \\
\text { by hPSCreg }{ }^{3} \text { to certify the hPSC for use in EC-funded research). } \\
\text { Approval by local ethics committees } \\
\text { Documentation to demonstrate any relevant ownership, licensing requirements, } \\
\text { restrictions for use and/or third party obligations }\end{array}$ \\
\hline
\end{tabular}

a The level of detailed characterization, such as phenotypic and molecular profiling, will vary depending on the application and use of the cell system.

\subsection{Basic culture procedures}

An in-depth description of basic culture parameters in accordance with GCCP is important for replication of the work and interpretation of experimental data. A consistent structure for SOPs should be established to enable ease-of-reading and clearly present key components, such as: 1) the list of reagents (including, when applicable, manufacturer, catalogue number, lot number, etc.), 2) the step-wise process and any incubation conditions required, 3) important technical and safety notes, and 4) criteria for the method used. For more comprehensive information on SOPs, see GIVIMP (OECD, 2018).

\subsubsection{Culture conditions}

For each cell culture system used, it is necessary to record the culture conditions, which should include the following:

- basal culture media applied

- type of serum, serum-free applications, or other supplements (e.g., growth factors, interleukins)

- culture media volumes used, feeding cycles

- culture vessel format and size

- incubation temperature, incubator atmosphere (such as carbon dioxide and oxygen levels where controlled), culture substrate used

\footnotetext{
$\overline{14}$ http://www.isscr.org/ (accessed December 20, 2021)

15 https://www.eurostemcell.org (accessed December 20, 2021)
} 
- elevation, if significantly above sea level (note that meteorological barometric pressures are conventionally normalized to altitude, while absolute or "station pressure" reflects true impacts on the culture atmosphere).

\subsubsection{Subcultivation of cells}

In order to demonstrate consistent and accurate cultivation procedures, it is important to record the following parameters:

- passage numbers of cell lines, recording the date of subcultivation to calculate subcultivation intervals (passage numbers may also be important when tracking cell line cross- and microbial contamination)

- split ratios and cell densities at culture seeding and harvest

- total length of time a cell line has been maintained in culture (see Tab. 5) to monitor aging and senescence, any genotypic and phenotypic drift, and extended passaging. To accurately document culture "age," the numbers of cells seeded and harvested will enable PDLs to be calculated, with an adjustment for plating efficiency of the cell culture and the specific culture medium used (Masters and Stacey, 2007).

- dissociation reagent used and length of incubation time

\subsubsection{Cell freezing, banking, and storage}

The way frozen stocks of cells are created is crucial, as it may impact on the quality of all future cell culture work. It is therefore important to assure that these procedures are performed reproducibly to standard protocols and documented, including details of:

- cell harvesting and the condition of harvested cells

- storage vial labelling

- freezing and storage of cells

- recovery of cells

- critical quality attributes

- batch designation

- size/aliquot numbers

- preparation of master cell banks and working stocks

- cryoprotectant and assessments of viability and plating efficiency after freezing

- the precise location of stored vials to assure an accurate inventory for reliable and rapid cell retrieval, even after years of storage - shipment details of cells (frozen or alive)

Information recorded on the storage vials is important to determine their origin when recovered for future work, and may include cell name/reference, passage number or PDL at preservation, freezing date when cryopreserved, and cell bank reference number and log record of storage condition. Note that inadvertent switching of cells thawed from cryovials and vial mislabeling are probably two of the most common causes of cell line cross-contamination.

In the shipment of cells, it is also important to address specific packaging and labelling requirements for safety regulations and standards in international shipment of biological material (see Principle 4), as well as records of maintenance of the cold-chain during shipment to assure they are received in optimum condition.

\subsection{Materials and equipment}

It is recommended to keep records of all factors, including deviations from standard procedures that could have a significant impact on the growth of cells, including reagents and equipment. The following sections summarize the kind of details that should typically be recorded. As a general note, for documentation of media and reagents used, the supplier and catalogue number should be recorded.

\subsubsection{Culture media and supplements}

Composition of culture media is one of the most influential factors on cell performance. Therefore, to enable scientific interpretation of the data and their independent replication, the following information should be recorded:

- composition of culture media for routine cultures (maintenance and growth media) and/or experimental cultures

- protocols for preparation of media, sterilization, and storage of media and equipment

- media additives (including serum)

- description of experimental procedures and downstream processing of cultures, e.g., cell harvest, isolation of cell culture products, virus propagation, vaccines, etc.

- any differentiation conditions used, i.e., chemical reagents and physical conditions

- expiry dates recorded on any reagents and lab media preparations

- labelling and disposal of cell culture laboratory waste (appropriate disposal of laboratory waste in order to prevent exposure of personnel and environment to infectious hazards and to prevent contamination)

This information can be kept in central lab records or even centralized departmental records. For cell cultures under particular standards and regulation, there may be specific requirements. For media components of animal origin, the details of species of origin and source laboratory and/or catalogue numbers should be kept. In addition, any processing of these reagents and microbiologicals or other testing may be important to assure absence of contamination for certain applications. For sera, the type (fetal, donor, adult, etc.) and origin (e.g., US origin, USDA approved, EU approved, etc.), company data sheets, certificates of origin, treatment of serum (heat-inactivated, irradiated, dialyzed, etc.), batch/lot numbers, and batch testing records (where required) should be kept. For use of cells in manufacturing products or cell therapies, a serum audit trail, providing traceability back to the original farm or a certification of the product by a regulatory authority, may be required.

\subsubsection{Culture glass, plasticware, and coating substrates}

Use of different substrates to grow cells can have significant impact on cell growth and differentiation. Therefore, it is important to record details on the culture surfaces, which may include:

-Culture vessels (type and supplier of flasks, petri dishes, bottles, roller cultures, etc.)

-Culture substrate, type, and supplier of coating material, e.g., collagen, fibronectin, laminin, poly-D-lysine, Matrigel ${ }^{\circledR}$, etc.

- Preparation of coating materials and coating procedures

- Freeze and thaw expiry date when re-freezing reagents are used

\subsubsection{Equipment}

A variety of equipment used for the manipulation, maintenance, and storage of cell cultures can impact on the viability, sterility, 
and performance of cell cultures, and it is necessary to check and monitor their correct performance. Key elements of equipment records are:

- Class II BSC: records of cleaning, maintenance, and of regular cabinet performance tests (see also Principle 2 requirements for data recording)

- Incubators: sterility, humidity (i.e., checks on humidification trays if fitted), and monitoring and calibration of temperature and atmosphere (typically carbon dioxide, nitrogen, or "multigas" systems)

- Autoclaves and other sterilization apparatus: records of disinfection conditions over time, results of biological or chemical disinfection indicators used (see also Principle 2 for data recording requirements).

- Cold storage, including refrigerators, freezers, and liquid nitrogen vessels: checks for correct function of alarms, temperatures, and/or liquid nitrogen levels

\subsection{Record storage and archiving}

As described above, it is recommended that comprehensive primary records of all details concerning the cell culture system are collected, including establishment of the cell line and tissue source, as well as origin of cells and tissues, their characterization and cell authentication, the culture methodologies, and the type and sources of cell culture materials (including culture media, media additives, and the plasticware in use). Monitoring and maintenance records are typically kept in association with the respective equipment, whereas the cell bank records for particular cell lines may be best centralized in a cell line file or as required under any formal standards. For those workers developing cell and tissue culture methods, the guidance in GIVIMP (OECD, 2018) is recommended.

Details of all routine and experimental culture procedures, and of the results obtained, may be recorded as they are generated and kept in hard-copy and/or electronic lab books with numbered pages. Raw data must be attributable, legible, contemporaneous, original, and accurate (ALCOA) (OECD, 2018).

Documents obtained in the process of securing ethical approval to use human or animal tissues (Tab. 4) must be kept on longterm record as a prerequisite for publications and should meet the requirements of the relevant authorities. In many countries, very detailed records of all animals used in experimentation will need to be kept and reported to national authorities.

Furthermore, periodical training, instruction of personnel in safety procedures, and training plans should be kept on file (see Principle 6), and such files for individuals may be a regulatory requirement for some applications.

\subsubsection{Recording of data}

Routine generic procedures, such as culture media preparation, culture maintenance, feeding and passaging of cells, freezing of cells, cell banking, etc., should be performed according to SOPs. Description of routine procedures can be kept on standard forms to assist in making performance of such procedures consistent (for details see Tab. 4-6). Records may also need to be kept for use and storage of cultures containing pathogens, GMOs, and radioactive materials. These records should comply with national and regulatory requirements. Records of environmental conditions (gas levels, temperatures) during cell handling in closed cell handling conditions should be part of the data record.

\subsubsection{Digital data}

Digitalization is now one of the most common formats for data recording, including the use of e-lab books, digital images, microphotographs, scans, read-outs of multi-plate readers, qP$\mathrm{CR}$ recordings, etc. These should be stored electronically on accessible laboratory computers and ideally be backed up, e.g., on backup data storage devices or server stations, keeping raw data secure and permanently accessible to every lab member. A routine should be established for regular backup of critical data.

Data storage and translation to new formats (or from hard copy to electronic versions) may need to be documented to meet the requirements of supervisory organizations or external regulators.

Processed data resulting from the analysis of raw data should also be securely stored, as well as the details of the analysis used to generate the results. This includes analysis methods, software versions, reference dataset versions, analysis package versions, pipelines and automated analysis workflows, and hardware and computer system configurations. Computer code used for analysis should be versioned and documented (for example, using github or svn) to ensure the reproducibility of the analysis. Data sharing following the FAIR (findable, accessible, interoperable, and re-usable) principles (Wilkinson et al., 2016) should be encouraged, especially for large high-throughput datasets. As an example, transcriptomic or whole genome sequencing datasets should be annotated with metadata and submitted to public repositories (i.e., Gene Expression Omnibus ${ }^{16}$, European Genome-Phenome Archive $^{17}$ ) to encourage data re-use and open evaluation by the scientific community. In the case of personally identifying data from human donors, data can be made available for re-use subject to the terms of donor consent for these sensitive datasets. Access to genetic data, for example, may be controlled by a data access committee, whose function is to ensure that requestors of controlled access data agree to abide by the data terms of use and importantly do not misuse the personal data of donor subjects.

Spreadsheets using pre-defined formulas, self-written equations, or macros (checked for accuracy) should be documented, validated (when implemented in electronic format), and disclosed, along with a description and justification of the controls used in the calculations, for example, in checking formulas for normalization accuracy. Other information that can be stored on laboratory computers includes Safety Data Sheets (SDS), certificates of analysis, certificates of origin, product information sheets, etc. For workers developing new in vitro methods, further useful guidance is included in Sections 10.2 and 10.3 of GIVIMP (OECD, 2018).

\footnotetext{
$\overline{16 \text { https://www.ncbi.nlm.nih.gov/geo/ (accessed 07.12.2021) }}$

17 https://www.ebi.ac.uk/ega/home (accessed 07.12.2021)
} 
Tab. 7: Some areas of concern in general laboratory safety to which risk assessment should be applied

\begin{tabular}{|c|c|}
\hline Operational issue & Examples of considerations to be taken into account \\
\hline $\begin{array}{l}\text { Facilities (such as laboratories, offices, storage, } \\
\text { and sanitation) }\end{array}$ & $\begin{array}{l}\text { Are the facilities appropriate and adequate for the intended use, well maintained, } \\
\text { and properly heated, ventilated, and illuminated? Are inventories of stored } \\
\text { hazardous materials and cultures kept? }\end{array}$ \\
\hline Security & $\begin{array}{l}\text { Depending on the work, are special security precautions required (for example, } \\
\text { for restricted access to site/laboratories and for removal of hazardous material } \\
\text { from the site)? }\end{array}$ \\
\hline Health and safety of staff & $\begin{array}{l}\text { Is the health and safety monitoring of staff regularly carried out and documented } \\
\text { and adequate personal protection provided? }\end{array}$ \\
\hline Laboratory equipment & $\begin{array}{l}\text { Is the equipment used certified as sufficiently safe for its specific and intended } \\
\text { purpose, according to the manufacturer's instructions? }\end{array}$ \\
\hline Infectious/biohazardous materials & $\begin{array}{l}\text { Are hazard classification, receipt, processing, containment, shipment, } \\
\text { storage, and disposal conducted correctly, with use of the appropriate protective } \\
\text { equipment, clothing, and other appropriate precautions? }\end{array}$ \\
\hline Chemicals and radioactive substances & $\begin{array}{l}\text { Are the receipt, handling, storage, and disposal of hazardous materials (for } \\
\text { example, radioisotopes, toxic compounds, flammable liquids) conducted according } \\
\text { to the procedures listed in the respective MSDS and compliant with national } \\
\text { regulation and local rules? }\end{array}$ \\
\hline Hazard prevention & $\begin{array}{l}\text { Are appropriate hazard prevention plans established, are staff regularly trained in } \\
\text { these procedures (for example, fire evacuations), and are they applied correctly? }\end{array}$ \\
\hline Waste disposal & $\begin{array}{l}\text { Is a waste management procedure established that ensures timely and } \\
\text { safe removal from the clean cell culture areas, followed by disposal according to } \\
\text { applicable government and local regulations? }\end{array}$ \\
\hline
\end{tabular}

\subsection{Documentation}

Effective and comprehensive communication is essential for cell and tissue culture work. It enables scientific personnel to understand and replicate procedures, eases intra- and inter-laboratory reproducibility, facilitates collaborations, and enables management and ultimately regulatory review processes for cellular systems used in a regulatory context.

The format of a report will depend on the target audience, e.g., in-house personnel, a client or sponsor, a regulatory body, the scientific community, or the general public. It should identify all persons responsible for the report. Where appropriate, the report should be formally authorized for its intended purpose.

A high-quality scientific report should include the authors and their affiliations, the objective of the work, the protocols and SOPs used (including details of reagents), planning and experimental design, controls used, the execution of the study, data collection and analysis, and a discussion of the outcome.

It is further recommended to clarify which parts of the study were performed in accordance with any relevant standards, laws and regulations, statutes, guidelines or guidance documents, including ethical, safety, and QA procedures (see Principles 4 and 5).

When submitting a report on cell and tissue culture work, a minimum set of information should be included, covering the origins of the cells, constraints of their use, their characterization, maintenance and handling, and the procedures used (see the scientific description for cell cultures described in Principle 1 and
Tab. 4 and 5). It is also helpful to include a statement of compliance with the GCCP principles. When the submitted report discusses the use of cells, tissues, or complex systems in the context of an in vitro method, a statement of compliance with GIVIMP principles is helpful. These issues, and those included in Tables 4 and 5, are important parts of in vitro method development, and useful guidance is given in GIVIMP (OECD, 2018).

\section{Principle 4: Establishment and maintenance of adequate measures to protect individuals and the environment from any potential hazards}

National and local laws, based on moral and ethical principles, govern safety in the workplace in most countries. Many countries also issue guidelines on occupational health and laboratory safety, and individual laboratories may also have rules that reflect local and institutional circumstances and regulations. Thus, the guidance on safety in the cell culture laboratory proposed here is not intended to supersede these laws and regulations, but rather draws attention to certain fundamental aspects of regulations and highlights issues specific to the in vitro culture of animal and human cells and tissues, as well as animal and human PSCs. The continuous introduction of novel laboratory technologies and reagents requires pre-emptive risk assessment, as safety regulations often cannot keep pace with technological progress. It is thus the responsibility of the individual laboratory to apply the 
Tab 8: Examples of precautions that may be used to ensure operator safety when handling cells and tissues

\begin{tabular}{|c|c|}
\hline Precaution 1 & Hands should be washed or disinfected before and after carrying out sessions of cell culture work. \\
\hline Precaution 2 & $\begin{array}{l}\text { An appropriate gown or laboratory coat should be worn (to be put on when entering the laboratory and removed } \\
\text { when leaving it). It is also wise to have separate gowns for quarantined cell lines and work with infectious } \\
\text { organisms. }\end{array}$ \\
\hline Precaution 3 & $\begin{array}{l}\text { Personal accessories (for example, rings, watches) that might compromise cell and tissue culture activities should } \\
\text { be removed or covered up to prevent them harboring contamination. }\end{array}$ \\
\hline Precaution 4 & $\begin{array}{l}\text { If appropriate, gloves should be worn and replaced immediately if torn or punctured, or during extended work } \\
\text { sessions. }\end{array}$ \\
\hline Precaution 5 & $\begin{array}{l}\text { When handling cell and tissue cultures, workers must avoid transferring potential contaminants from hands to } \\
\text { unprotected body parts (for example, eyes or mouth), clothing or items in the open laboratory environment, and } \\
\text { particularly items that are likely to be handled by other users, such as taps, light switches, and telephones. }\end{array}$ \\
\hline Precaution 6 & $\begin{array}{l}\text { As far as is reasonably practicable, all cell and tissue work should be performed in a Class II BSC or other } \\
\text { appropriate (micro)biological safety cabinet (see Appendix 61). NB: certain cabinets, such as horizontal laminar } \\
\text { flow cabinets, protect the cells and tissues, but not the user or the general environment. }\end{array}$ \\
\hline Precaution 7 & $\begin{array}{l}\text { An aspiration device (rubber bulb or electronic pipettes) should be used to pipette liquids. Mouth-pipetting must be } \\
\text { strictly prohibited. }\end{array}$ \\
\hline Precaution 8 & $\begin{array}{l}\text { All procedures should be undertaken using methods that minimize the production of aerosols that might spread } \\
\text { contamination by microorganisms or cells (examples of hazardous processes include centrifugation, vortex mixing, } \\
\text { and freeze-drying). }\end{array}$ \\
\hline Precaution 9 & $\begin{array}{l}\text { All disinfectants used should be effective and appropriate for the work (NB materials or liquids with high levels of } \\
\text { proteinaceous material may need use of disinfectants that can decontaminate such materials effectively, such as } \\
\text { phenolics). }\end{array}$ \\
\hline Precaution 10 & All work surfaces should be cleaned with an appropriate disinfectant before and after use. \\
\hline Precaution 11 & $\begin{array}{l}\text { The use of sharps should be avoided wherever feasible. Any used sharps should be disposed of safely according } \\
\text { to approved procedures. }\end{array}$ \\
\hline Precaution 12 & All cultures should be clearly and unambiguously labelled. \\
\hline
\end{tabular}

fundamental principles of laboratory safety also in the absence of regulation. In many countries, each laboratory is required to appoint a biological, chemical, and radiological (if applicable) safety officer, and this individual should receive suitable training and be involved in the safety evaluation of all cell culture procedures conducted in the laboratory. Individual workers also have a key role to play in identifying and evaluating hazard and risk and implementing safe working procedures.

\subsection{Risk assessment}

Identifying and evaluating risks, and taking appropriate action to avoid or minimize them, are at the foundation of a safe workplace. The laboratory environment contains hazards that are often complex and require specialized knowledge and experience. Key stages in the management of such risks are robust risk identification, establishment of procedures to manage the risks, and re-evaluation of residual risk to check that it has been reduced to an acceptable level. These assessments should be documented and reviewed at regular intervals to take into account any changes in local practice, national or international regulations, or changes in scientific knowledge. Risk assessments should provide a reference document for other individuals performing the work, and a regular training schedule should be established to en- sure awareness of the personnel. Risk assessment should consider the specific formulation and use of individual reagents, as this will affect potential exposure and toxicity.

It is important to pay particular attention to the risks specific to certain populations of workers. For example, women of childbearing age may be at greater risk from the effects of certain chemicals, such as teratogens or biological agents. Similarly, persons with a diminished immune response (for example, due to medication or a medical condition) should seek expert medical advice before they are allowed to work in a laboratory where cell and tissue culture work is performed.

The safety conditions highlighted below relate not only to the safety of laboratory staff carrying out cell culture work but also to the support staff - for example, those handling or disposing of the materials used in the laboratory. Furthermore, there may be theoretical risks for laboratory workers becoming infected and transmitting disease outside the laboratory or recombinant organisms, pathogens, or hazardous chemicals escaping the laboratory or being improperly disposed of. In such cases, the impact on the general public and the environment must be considered. Some of the areas of concern with regard to general laboratory safety, and to which it might be appropriate to apply risk assessment, are shown in Table 7. Hazards of particular concern 
in the cell or tissue culture laboratory are further discussed in Sections 4.2 and 4.3 , below.

Once a risk assessment has been carried out, all relevant personnel must be made aware of the potential hazards associated with their work and must be trained in the safe conduct of their work duties (typical precautions are shown in Tab. 8; see also Principle 7) and designated safety procedures. Moreover, they must know the appropriate use of the safety equipment required (e.g., personal protective equipment) and the appropriate handling of chemical spills.

Further helpful guidance can be found in Section 3.2 of GIVIMP (OECD, 2018).

\subsection{Hazards related to cell and tissue culture work}

Hazards can be categorized into three main groups: physical hazards, chemical hazards, and biological hazards. A risk assessment plan should consider all these hazards in relation to the proposed work. As already mentioned, this assessment should not be limited only to the laboratory and laboratory personnel but should also cover risks to people in the entire facility, people in the external environment, and the environment itself. This is not only a vital aspect of basic research and testing but is particularly important when cultured cells and tissues are used for diagnostic purposes or for producing therapeutic products, or when the cells and tissues themselves are used for therapeutic purposes.

\subsubsection{Physical hazards}

The cell and tissue culture laboratory does not pose any specific physical hazards. PSC and microphysiological/3D systems are not typically associated with physical hazards different from other cell cultures. In general, the main physical hazards in the cell and tissue culture laboratory are associated with the use of pressurized gases, for which there are specific government safety regulations (e.g., Directive 2014/68/EU (EU, 2014)). However, incorrect use of devices, and particularly those using extreme heat (e.g., autoclaves, incinerators), pressurized steam or gases, irradiation, and mechanically hazardous components (e.g., centrifuges, sharps such as needles, razor blades, potentially explosive components) is a major source of hazard and should be managed under the appropriate legislation and local safety rules for use and maintenance. Laboratories and workspaces should always be kept clean and well organized. It is wise to avoid storage of heavy objects or large glass vessels above typical head height or storage of material on the floor or anywhere it can cause risk to people.

Any equipment or apparatus used should meet national safety guidelines. Equipment such as autoclaves, centrifuges, laminar flow or microbiological safety cabinets, and gas supply cylinders should have a program of maintenance and checks on correct operation for safe use carried out according to the manufacturer's instructions. Special attention, including formal staff training, should be paid to assure staff can safely use equipment that carries specific hazards, such as high voltage, ultra-violet light, lasers, radioisotopes, liquid nitrogen, and extreme temperatures and pressures (e.g., liquid nitrogen, autoclaving, use of pressurized gas). Handling of liquid nitrogen carries the hazards of cold burns (frostbite) and asphyxiation due to rapid expansion of gaseous nitrogen (examples of handling precautions are given in Appendix $4^{1}$ ).

\subsubsection{Chemical hazards}

A laboratory using cell and tissue culture should not be a particularly dangerous place to work with regard to chemical hazards as long as safe work practices are established and enforced. However, some chemicals have ill-defined or unknown biological effects, so general safety standards should always be maintained to protect workers against these uncertain hazards, including volatile reagents. Safety Data Sheets (SDS) for all chemicals used in the laboratory should be requested from the suppliers and used in developing risk assessment. For any substances that are potentially hazardous to health (for example, mutagens, cryoprotectants, labelling dyes), SDS data should form the basis of a risk assessment for the use of these chemicals. The level of risk, for example, will depend on the formulation of the reagent, the quantities being used, the techniques being employed, the type of personnel using them, and the like. Control of storage is covered by national legislation in most countries as chemical-specific waste disposal procedures.

Particular care should be taken with certain kinds of materials, such as teratogens, which put women of childbearing age at risk. Some materials used in in vitro toxicity tests (e.g., mutagens, carcinogens, and neurotoxicants) represent a particular problem, particularly if the study requires that they be anonymously coded and supplied via an independent, external source. Although the concentrations used in the final test solutions may be very low, the storage of the bulk material and its handling can represent a significant potential risk, particularly if blinded. It should always be possible to break the code quickly in the event of an accident.

\subsubsection{Biological hazards}

Many different issues related to potential biological hazards (e.g., infectious agents, mitogens, allergens, cytotoxins) must be considered, recorded, and monitored in special cases. Potential biological hazards originate from (1) the cultured cells, (2) the culture media supplements, and (3) the culture techniques and experimental protocols applied, such as immortalization, transformation, or transfection of cultured cells. Also, when using cells in new culture systems, workers should be alert to unexpected changes in the cells that could indicate reactivation or expansion of a viral contaminant. There is also the possibility that cells may be inadvertently or deliberately contaminated with pathogens after donation.

Risk assessments for primary tissues/cells and cell lines should address issues that could arise from the species of origin, the health status of the donor, the available data from microbiological donor screening tests, the culture and storage history, and in the case of iPSC lines, the vector clearance/silence status. In general, human and primate cells (including hESCs and iPSCs) are considered of highest risk of carrying human pathogens (Stacey and Hawkins, 2017), although it is important to bear in mind that cells from other species can also harbor serious human pathogens (Stacey, 2007; Mahy et al., 1991; Petricciani et al., 2017). The 
health status and geographical origin of human cell or tissue donors should also be considered, and donor-screening procedures such as virological screening for key pathogens and lifestyle questionnaires can be useful in risk assessment. For all sources of cells, the availability of data from microbiological screening tests will help mitigate risk, and the culture and storage history may be useful in flagging potential hazards from reagents and costored materials (Frommer et al., 1993; Fountain et al., 1997). Although not usually dangerous to the user, cells and tissues have the potential to permit the replication of viruses that are pathogenic to humans (occasionally with tragic consequences (Zhang et al., 2010; Lloyd et al., 1984)) and should, therefore, be routinely treated as potentially infectious (Tab. 8).

In the case of cells intended for transplantation, there are established requirements for donor selection, processing, testing, storage, and supply (EU, 2006a; FDA, 2001). However, for cells intended for more complex therapies, and particularly involving cell culture and application in large numbers of patients, it is wise to consider additional microbiological risks (Petricciani et al., 2017; SaBTO, 2014). It may not be possible to screen for all potential contaminants for practical reasons of time and costs, and whilst new molecular techniques, such as massive parallel sequencing/whole genome sequencing, may offer more economic solutions, they have yet to be standardized for routine use. However, approaches that may be employed in risk assessment include post-donation donor assessment for acute infections and consideration of factors that elevate risk of contamination by viruses that may replicate in cell culture and/or may cause human cell transformation (Petricciani et al., 2017).

In a number of cell culture procedures, the cell type of interest is cultured on a "feeder layer," i.e., another cell type that supports its growth. Feeder cells may be primary cell cultures derived from a tissue or a cell line. They are treated to inhibit their division (e.g., mitomycin C, $\gamma$-irradiation). Such cell cultures are a potential source of contamination and should be prepared as cryopreserved cell stocks and subjected to QC and safety testing according to the same principles applied to other cell cultures.

All cells and tissues new to the laboratory should be handled under a strict quarantine procedure, including suitable precautions to prevent the spread of potential contamination, according to the basic guidance given in Table 8, with additional controls as necessary (such as the use of separate dedicated media and equipment, and handling by dedicated staff). The biological risk of infected cell cultures depends on the hazard category of the potential infecting pathogens. Viral contamination needs particular attention because infection may be without cytopathic effect for the cell culture or may be latent (e.g., herpes virus, EBV) and hard to detect. In general, the hazard potential of infectious agents determines the degree of containment and biosafety level, respectively. Furthermore, it is advised to culture initial primary cultures in a quarantined laboratory. After the primary cells are sub-cultured into cell lines and subsequent diagnostic tests do not reveal any specific contamination, then the material may be cultured together with other stocks. A comprehensive risk assessment and risk management process is mandatory and its execution and/or implementation of consequences need to be incorporated into the safety training program. Cell cultures should be handled in a Class II BSC (see Appendix $6^{1}$ ). Horizontal laminar flow cabinets may be used for non-hazardous media preparation, but should never be used when handling cells, as such cabinets are designed to protect only the work area, and the air flow is directed toward the worker and would expose them to any contaminants in the cell culture (see Principle 2, Section 2.2).

Where the nature of the work involves a significant risk of biological hazard, special precautions must be taken in accordance with national requirements. Where named infectious organisms are involved, these requirements are based on the World Health Organisation classification for human pathogens (Appendix $7^{1}$ ).

If the cells or tissues originate from a certified source, such as a registered biobank, which provides certification of freedom from certain contaminants, this documentation may suffice for risk assessment, provided that the cells have not been exposed to potential sources of contamination since leaving the bank. However, it is recommended that, as a minimum and where advisable, mycoplasma testing should be carried out on all samples received.

Laboratory workers' immune systems may not protect them against some hazards, such as the tumorigenic growth of their own cells, which may have been altered via in vitro procedures (for example, by transformation, reprogramming, immortalization, infection, or genetic modification). Accordingly, most national guidelines make it unacceptable for operators to culture cells or tissues derived from themselves or from other workers in the same laboratory, nor to genetically manipulate such cells or tissues or treat them with potentially pathogenic organisms.

Recombinant cells (i.e., those produced by genetic engineering or genetic modification ${ }^{18}$ ) will generally fall within the requirements of such guidelines. The classification and control of this kind of work differs between countries, and countries may decide to classify work at a higher or lower risk level when new information on a particular vector/host system becomes available (for an example, see the EU GMO contained use regulations, EU, 2009).

Risk assessment is clearly a dynamic process and must take into account other risk assessments and the progress of science. It is the responsibility of the laboratory safety manager to keep up to date with developments in this rapidly evolving field, amend the lab regulations accordingly, communicate the changes to staff, provide additional training if required, and to be in compliance with national and international guidelines.

With specific respect to iPSCs, it is important to note that where the recombinant vectors remain in the genome, in many countries they will remain subject to GMO regulation when used and also when stored or disposed of. Where vectors are non-integrating and temporary, there must be evidence to assure removal of the recombinant DNA components to enable them to no longer be subject to GMO regulatory controls for those vectors.

\footnotetext{
18 Terms used to cover most techniques that artificially alter the genetic make-up of an organism by mixing the nucleic acids of different genes and/or species together.
} 


\subsection{Risks to the environment}

Pathogens or GMOs may present a risk to the environment where they are able to survive. Such risks are increased in workplaces with poor sterilization and waste disposal practices, leading to contamination of water, air, or soil, or escape from containment. The environment can also be contaminated by release of biological material resulting from accidents, including transport accidents, and systems should be put in place either to prevent or minimize the potential for such events. Support from the local biological safety officer should be sought, if available. Since animal cells are not capable of independent growth in the environment, there are no special concerns for cell and tissue culture systems with respect to environmental release. However, there are concerns about germline transmission of genetic alterations for patients in clinical trials, and new technologies such as stem cell research techniques and gene editing will need to be considered carefully ${ }^{19}$.

\subsubsection{Waste disposal}

Risks to the environment are generally due to poor waste disposal, leading to contamination of water, air, or soil, or the escape from containment of hazardous materials. Methods of waste disposal appropriate to the work in hand must be identified during the risk assessment and risk management process. These methods must protect not only the individual tissue culture workers themselves, but also their colleagues, the wider population, and the environment. Work with known pathogens and GMOs must be performed according to the relevant regulations, including methods of waste disposal. Where methods are not specified in these regulations, there is a requirement to assess and justify all proposed methods of waste disposal as part of the risk assessment. Similarly, the appropriate method of disposal of hazardous chemicals must be identified before work with them is undertaken.

In line with the above precautionary principle, the following minimum precautions should be taken when disposing of waste from the cell culture laboratory:

- All liquid waste, with the exception of sterile media or solutions, should be either chemically inactivated (by using sodium hypochlorite or another disinfectant) or autoclaved before disposal.

- All solid waste contaminated with tissue culture liquid and/or cells should either be autoclaved before leaving the laboratory, or should be placed in rigid, leak-proof containers before being transported elsewhere for autoclaving or incineration.

- Avoid storage of waste in the laboratory. Waste should be removed daily or contained to prevent contamination of the work.

\subsubsection{Transport}

The transportation of any biological materials, chemicals (including liquid nitrogen), or other materials (for example, dry ice) of potential risk to humans, animals, plants and/or the environment, and shipment of tissues and cell cultures must comply with national or international regulations (see, for example International Air Transport Association (IATA) dangerous goods ${ }^{20}$ ). Under these regulations, a tissue or cell culture may fall into any one of four classes of biological material used for shipping purposes, namely:

- diagnostic specimens

- infectious specimens

- biological products

- GMOs

These classifications will dictate the specific requirements for shipment. The tissue or culture should be packed to prevent leakage or spills in the case of breakage, be correctly labelled (with appropriate hazard symbols), and have the appropriate accompanying documentation (SDS import form, export form, and CITES $^{21}$ permit and provisions of the associated Nagoya proto$\mathrm{col}^{22}$, if applicable).

A typical SDS for a cell line is shown in Table 9. Wherever appropriate, the IATA guidelines ${ }^{23}$ should be followed, as they are stringent and recognized internationally. Before arranging transport, the various legal requirements for export and import into the recipient country should be considered, including, for example:

- ethical issues (such as the use of human cells or tissues of embryonic origin)

- disease transmission (including infectious disease of significance in agriculturally important species)

- endangered species regulations ${ }^{21}$

- bioterrorism regulations

\section{Principle 5: Compliance with relevant laws and regulations, and with ethical principles}

\subsection{General considerations}

For cell and tissue culture, it is usually a legal requirement to ensure accountability, health and safety, and ethical practices, regardless of cell type used. While there are no international laws governing cell and tissue culture procedures, national and international regulations and laws cover the procurement, use, and storage of cells and tissues, their genetic manipulation, and other safety issues. These regulations and laws, as well as any other applicable legal or ethical guidelines, must be carefully considered before any study is initiated. Such consideration will also ultimately support a higher quality study that produces data in which all parties can have confidence.

\footnotetext{
19 http://nuffieldbioethics.org/wp-content/uploads/Genome-editing-and-human-reproduction-FINAL-website.pdf (accessed December 7, 2021)

$20 \mathrm{https}: / /$ www.iata.org/en/programs/cargo/dgr/ (accessed December 7, 2021)

21 https://www.cites.org (accessed December 7, 2021)

$22 \mathrm{https://www.cbd.int/abs/text} \mathrm{(accessed} \mathrm{December} \mathrm{7,} \mathrm{2021)}$

23 https://www.iata.org/publications/Pages/standards-manuals.aspx (accessed December 7, 2021)
} 
Tab. 9: Typical content of a cell culture basal medium Safety Data Sheet (SDS) (example data in italics)

\begin{tabular}{|c|c|}
\hline \multicolumn{2}{|c|}{$\begin{array}{l}\text { Cultures are not specifically defined as hazardous materials, but as live cells they present potential biohazards and should } \\
\text { be treated as biohazardous. }\end{array}$} \\
\hline \multicolumn{2}{|c|}{ Emergency Telephone Number: To be used only in the event of an emergency involving a spill, leak, fire, exposure, or accident. } \\
\hline $\begin{array}{l}\text { SECTION 1: } \\
\text { Identification of the } \\
\text { substance/mixture and of } \\
\text { the company/undertaking }\end{array}$ & $\begin{array}{l}\text { Product code } \\
\text { Product name } \\
\text { Supplier name and contacts } \\
\text { Local emergency contact numbers }\end{array}$ \\
\hline $\begin{array}{l}\text { SECTION 2: } \\
\text { Hazards identification }\end{array}$ & $\begin{array}{l}\text { General hazard identification } \\
\text { GHS classification }{ }^{\text {: }} \text { health, physical, and environmental hazards } \\
\text { Label elements, e.g., signal word, hazard pictogram/name, hazard statement } \\
\text { Precautionary statements (prevention, response, storage, disposal, other hazards) }\end{array}$ \\
\hline $\begin{array}{l}\text { SECTION 3: } \\
\text { Composition/information on } \\
\text { ingredients }\end{array}$ & $\begin{array}{l}\text { Statement on components which at a given concentration are considered to be hazardous } \\
\text { to health. }\end{array}$ \\
\hline $\begin{array}{l}\text { SECTION 4: } \\
\text { First aid measures }\end{array}$ & $\begin{array}{l}\text { Statement on emergency measures for skin contact, eye contact, ingestion, symptoms } \\
\text { (acute and chronic), immediate medical attention, and treatment needed. }\end{array}$ \\
\hline $\begin{array}{l}\text { SECTION 5: } \\
\text { Firefighting measures }\end{array}$ & Suitable and unsuitable fire extinguishers, special hazards, and information for fire fighters. \\
\hline $\begin{array}{l}\text { SECTION 6: } \\
\text { Accidental release measures }\end{array}$ & $\begin{array}{l}\text { Personal precautions, protective equipment and emergency procedures, environmental } \\
\text { precautions, methods and material for containment and cleaning up. }\end{array}$ \\
\hline $\begin{array}{l}\text { SECTION 7: } \\
\text { Handling and storage }\end{array}$ & $\begin{array}{l}\text { Precautions for safe handling, conditions for safe storage, including any incompatibilities and } \\
\text { specific end use(s) (such as cell therapy). }\end{array}$ \\
\hline $\begin{array}{l}\text { SECTION 8: } \\
\text { Exposure controls/ } \\
\text { personal protection }\end{array}$ & $\begin{array}{l}\text { Control parameters (Exposure limits, engineering measures, exposure controls) } \\
\text { Personal protective equipment (respiratory protection, hand protection, eye protection, skin } \\
\text { and body protection), and hygiene measures }\end{array}$ \\
\hline $\begin{array}{l}\text { SECTION 9: } \\
\text { Physical and chemical } \\
\text { properties }\end{array}$ & $\begin{array}{l}\text { Odor, } \mathrm{pH} \text {, evaporation rate, flammability (solid, gas), upper explosion limit, lower explosion limit, } \\
\text { vapor pressure, partition coefficient: } n \text {-octanol/water, explosive properties }\end{array}$ \\
\hline $\begin{array}{l}\text { SECTION 10: } \\
\text { Stability and reactivity }\end{array}$ & $\begin{array}{l}\text { Reactivity } \\
\text { Chemical stability } \\
\text { Possibility of hazardous reactions } \\
\text { Conditions to avoid } \\
\text { Incompatible materials } \\
\text { Hazardous decomposition products } \\
\text { Melting point/melting range } \\
\text { Boiling point/boiling range/flash point/autoignition temperature/decomposition } \\
\text { Decomposition temperature }\end{array}$ \\
\hline $\begin{array}{l}\text { SECTION 11: } \\
\text { Toxicological information }\end{array}$ & $\begin{array}{l}\text { Information on toxicological effects } \\
\text { Principal routes of exposure potential health effects (e.g., irritation, corrosivity, sensitization, } \\
\text { Specific Target Organ Toxicity (STOT) - Single Exposure/Repeated Exposure, carcinogenicity, } \\
\text { mutagenicity, reproductive toxicity, aspiration hazard) }\end{array}$ \\
\hline $\begin{array}{l}\text { SECTION 12: } \\
\text { Ecological information }\end{array}$ & $\begin{array}{l}\text { Toxicity, persistence and degradability, bioaccumulative potential results of PBT and } v P v B \\
\text { assessment }\end{array}$ \\
\hline $\begin{array}{l}\text { SECTION 13: } \\
\text { Disposal considerations }\end{array}$ & Waste treatment methods \\
\hline $\begin{array}{l}\text { SECTION 14: } \\
\text { Transport information }\end{array}$ & $\begin{array}{l}\text { IATA/ADR/DOT-US/IMDG (e.g., UN Number, UN proper shipping name, transport hazard, packing } \\
\text { group) }\end{array}$ \\
\hline $\begin{array}{l}\text { SECTION 15: } \\
\text { Regulatory information }\end{array}$ & International inventories by country \\
\hline $\begin{array}{l}\text { SECTION 16: } \\
\text { Other information }\end{array}$ & $\begin{array}{l}\text { Revision number and date } \\
\text { References (e.g., ECHA }{ }^{24}, \text { TOXNET }^{25} \text {, eChemPortal } \\
\end{array}$ \\
\hline
\end{tabular}

a The Globally Harmonized System of Classification and Labelling of Chemicals (GHS)

24 http://echa.europa.eu/ (accessed December 7, 2021)

25 https://www.nlm.nih.gov/toxnet/index.html (accessed December 7, 2021)

26 http://www.echemportal.org (accessed December 7, 2021) 


\subsection{Use of human cells and tissues}

Before any human material is used for the establishment of a new cell line, ethical approval should be obtained from the relevant authorized persons (e.g., individual, individual's family, or other authorized persons). The removal of tissue samples from human volunteers should only be performed by qualified and authorized personnel, and risks should always be minimized by following standard biosafety precautions. Of course, human volunteers should also be considered donors, and the aforementioned informed consent should be obtained and documented. Consideration should also be given to the potentially ethically sensitive issue of whether donors can be paid for their donation. Products developed based on human cell lines for the manufacture of cell therapies are closely regulated in the EU and US as investigational medical products and are subject to market authorization by the European Medicines Agency or the US FDA (EC, 2007; EU, 2001b; FDA, 2013, 2015a,b,c), respectively.

It is particularly important that researchers are aware of the need to handle human cells and tissues in a responsible manner and in accordance with donor consent and local and national requirements. Confidentiality with respect to the provision and use of human tissue is governed by both national and international laws and professional guidelines. In addition, most countries require that informed consent be sought from the donor or donor's family (or other authorized persons) when obtaining cells or tissues from human donors, and thus this should be considered an essential first step in acquiring such materials. Requirements for acceptable informed consent may vary between and even within legal jurisdictions, and the investigator obtaining the tissues must ensure compliance with all applicable laws, regulations, and local rules, e.g., the US NCCUSL Revised Uniform Anatomical Gift Act (NCCUSL, 2006), the UK Human Tissues Act (UK, 2004), EU regulations comprising three EC Directives: the parent Directive 2004/23/EC, which provides the framework legislation, and two technical Directives, 2006/17/EC and 2006/86/ EC, which give detailed requirements (Pirnay et al., 2015). Consent should be "fit for purpose" and should cover all intended uses of the tissue.

Regarding traceability of tissues and cells used as starting materials in a medicinal product for the EU, Directive 2004/23/EC (also known as the European Tissues and Cells Directive) (EU, 2004) covers standards for donation, procurement and testing, processing, preservation, storage, and distribution of human tissues and cells for use in humans ${ }^{27}$. This legal framework includes four separate technical implementing directives covering: 1) donation, procurement and testing of human tissues and cells; 2) traceability, notification of serious adverse reactions and events, and requirements for processing, preservation, storage, and distribution of human tissues and cells; 3 ) coding of human tissues and cells; and 4) verifying the equivalent standards of quality and safety of imported tissues and cells. The European Commission-sponsored TISS.EU project published a 2011 re- view of guidelines on biobanking and biomedical research in EU countries, with the goal of ultimately yielding harmonized legal and ethical guidelines ${ }^{28}$. In the US, donor selection criteria are based on those described in Part 21 Code of Federal Regulations 630 (FDA, 2019a) and 606 (FDA, 2019b).

Transportation of human tissues, both nationally and internationally, is also carefully regulated ${ }^{20}$. For a specific example, European legislation for the import and export of tissues for clinical use (EU, 2012, 2006a,b,c) regulates cell and tissue procurement, processing, storage, and testing. Only couriers who have demonstrated knowledge of local requirements for import, can track shipments, and have emergency procedures in place where cryogens become depleted should be used. Personnel at hospitals and human tissue banks are knowledgeable about the relevant regulations and are thus best equipped to advise on the complex issues (e.g., ethics, consent, safety, and logistics) involved with procurement and transportation. However, regardless of the tissue source, researchers are individually responsible for ensuring that ethical procurement and personal data protection requirements are adequately addressed. Data held on donors of tissue used to generate cell lines may also be subject to regulations, such as those existing in the US (FDA, 2001, 2010) and EU (EU Directive on Data Protection (EU, 1995)) superseded by the General Data Protection Regulation (EU) 2016/679 (GDPR) in 2016. Such regulations have significant implications for interactions between research groups where personal data include exchange of genetic sequences. Even where specific regulations do not exist, compliance with good practice in this area is recommended. Additional controls on donor information may also apply in some countries.

Cell line ownership may mean that there are restrictions on their use even for research purposes.

Ownership and patents can be complicated, as several parties may be involved in the negotiation of their use. For human cell lines, these parties could include: the hospital authority and clinicians where the original tissue sample was taken, the scientists engaged in deriving and researching the cell line, the institution that hosted the research, sponsors (such as funding bodies or collaborating commercial companies), and those who developed enabling technology, such as cell reprogramming. Depending on the nature of consent, the tissue donor may also need to be consulted.

Given the heightened ethical concerns associated with the use of human embryos for research, including the generation of hESCs, these materials may be prohibited or regulated under strict legislation. Thus, any researcher proposing to generate hESCs must ensure that all national laws and regulations and local organization rules are in compliance with the relevant jurisdictions of origin of the cells and where they are to be used. It is also important to note that consent may need to be specific for hESCs and include consent to carry out genetic testing. There may be controls and, in some cases, prohibition on the procurement and use of the original donor tissues or cells, as well as on the generation and use of cell lines from these materials (Seltmann et al., 2016; An-

27 https://www.ema.europa.eu/en/human-regulatory/overview/advanced-therapies/legal-framework-advanced-therapies (accessed December 7, 2021)

28 https://cordis.europa.eu/result/rcn/91320_en.html (accessed December 7, 2021) 
drews et al., 2015). Other ethical issues can arise with iPSC technology, where cell donors are often still alive and can possibly be identified. This is particularly challenging where fetal tissues are the donor source, given their associated ethical concerns. See Andrews et al. (2015) for a detailed discussion of requirements for establishing hPSC stocks for clinical application. The use of complex systems such as human organoids transplanted into animals may also need to be considered (Bredenoord et al., 2017).

\subsection{Use of animal tissues}

Many of the best practices for human cells and tissues described above are also relevant to procurement and use of animal tissues. A central issue for any work that involves tissues harvested from animals is that it is compliant with relevant national legislation as well as the 3 Rs principles (replacement, reduction, and refinement) first described by Russell and Burch (1959). Many cells and tissues are being used or intended as replacement alternatives to animal experiments, thereby also helping to solve the ethical issue of animal use. However, other ethical and legal issues may arise for cells and tissues obtained from non-human animal materials. For example, rodent tissues are often used as a source for feeder layer cells to support the cellular microenvironment for a target cell population; these should be obtained using good practices for the maintenance of laboratory animals (EU, 2010;29). These practices include colony screening to exclude the presence of key pathogens and the use of approved animal husbandry practices. Such requirements will usually include the lab isolating the animal tissues to have a license for the procedures, staff, and laboratory facility. It should also be mentioned that there could also be ethical issues related to the use of animal cells/tissues in therapy for humans that need to be addressed.

Other international agreements may impact the transfer of certain cell lines based on circumstances (e.g., animal-derived cells and tissues that are found to be infected with viruses that could infect wildlife or species of agricultural importance, creating a potential for animal virus contamination), but such constraints on shipment will need to be confirmed locally in discussion with national or regional authorities. Careful monitoring and prompt reporting to the relevant authorities of any such adventitious agents that are detected in cells or tissues must be undertaken ${ }^{30}$. Use of certain animal-derived products can also raise both ethical and legal issues. For example, the manufacture of basement membrane extracts and fetal calf serum is ethically problematic (see references in (van der Valk et al., 2018). These concerns can be addressed by the use of human serum, synthetic alternatives, or serum-free preparations, provided optimal culture conditions can be maintained. Fire emergency procedures may also require that a formal list of hazardous materials is maintained, including cells harboring infectious organisms.

The creation of cell lines involving the introduction of recombinant DNA vectors means that such cells are considered GMOs, and their creation, storage, transport, use, and disposal are sub- ject to the requirements that apply to other GMOs. This applies also to systems where the vectors are removed or do not become integrated into the genome but may persist in other forms in the cell and will still be considered as genetically modified, and even to cells modified by gene-editing techniques (for example, where Cas-9 constructs become endogenously expressed - see Section 2.3). Purely chemical means of inducing pluripotency, however, are unlikely to be included in this group. Any viral vectors used should be modified to prevent release of infectious virus from reprogrammed cells, and this should be checked as part of normal laboratory risk assessment procedures. This is a rapidly expanding field, and since it involves manipulating genes and cells in ways that do not occur in nature, for which the long-term consequences are yet unknown, it raises sensitive ethical and safety issues. Genetic manipulation experiments are regulated in the EU (EU, 2001a), USA (FDA, 2015a,b,c), and in many other countries, where relevant approval must be sought before any work is initiated.

\section{Principle: Provision of relevant and adequate education and training for all personnel to promote high-quality work and safety}

Cell culture applications are expanding and evolving rapidly as they are used in multidisciplinary fields. Cell biology, genetics, bioengineering, and the use of biomaterials are becoming more integrated and thus require an extensive range of procedures and techniques. However, there are some preparative and manipulative skills that are common for all in vitro culture procedures that are fundamental to assuring good-quality data from cell culture work. Adequate training of staff to perform their duties in a laboratory is essential to ensure that work is performed according to the standards of the organization in relation to its scientific, legal and safety requirements, and obligations.

A fundamental understanding of the scientific procedures and principles involved in laboratory work is vital and will also improve safety awareness; therefore, promotion of continuous education for staff in new scientific developments and emerging issues is important.

Special attention is required with the recruitment of new staff. Knowledge and capabilities of new personnel need to be assessed in order to plan further training procedures required for their specific work (e.g., SOPs, general laboratory maintenance, and safety and emergency procedures).

Training should be an ongoing and planned process focused on improving and developing practical skills that help maintain adequate competence. To ensure the quality and safety of work in the long term, it is also important to link training with personal development programs for technical and scientific staff to ensure they are progressively trained, educated, and updated in line with changing laboratory activities and demands.

\footnotetext{
29 https://olaw.nih.gov/policies-laws/phs-policy.htm (accessed December 7, 2021)

30 https://www.oie.int/en/what-we-do/animal-health-and-welfare/animal-diseases/?_paged=4 (accessed December 7, 2021)
} 
In some cases, training can be provided in-house by experienced members of staff or can be performed by visiting experts, on-line programs, and/or through attendance of external courses.

The main areas of training are laboratory procedures, general cell culture procedures, advanced and specialist cell culture procedures, documentation, and safety and laws/regulation.

\subsection{Laboratory training}

The trainee or new employee needs to be familiar with the laboratory, meet the other staff, and determine their roles and responsibilities (Freshney, 2016). Moreover, understanding of the nature and purpose of SOPs facilitates the adequate performance of experiments to obtain good-quality data. Training on equipment handling is normally taken up by senior staff with pre-existing knowledge or working with the suppliers; however, specific training on the different apparatus is recommended to avoid damage or inappropriate use. In addition, training on maintenance and calibration of the machines should be incorporated into initial laboratory training. For example, laboratory workers should be aware that the use of uncalibrated or wrongly calibrated machines could lead to erroneous results (see Principle 2, Section 2.2).

Safety and hazard management is one of the most important elements in training for cell culture. Each laboratory worker should know the risk of all the elements required during their performance. Knowledge of the risk of the reagents, equipment, and biological material used, together with biological and harmful material waste and its appropriate disposal, is recommended to protect the operator and the environment (see Principle 4). For example, the use of a corrosive reagent without knowledge of its toxicity or without adequate protective gear could lead to occupational injuries.

\subsection{Culture procedures}

Currently, there is a lack of cell culture training in the early career stages of laboratory workers. Ideally, a good basic education on cell culture handling and aseptic techniques (Tab. 10) should be the first requirement, and integrating them as early as possible in the staff's career is recommended (Hartung et al., 2009). This will set the basis for more advanced future training. Training on the specific cell or tissue culture in use (e.g., isolation techniques, cell counting, cryopreservation, mycoplasma testing) (Tab. 10) is recommended. For example, during cryopreservation, the incorrect application of a procedure or SOP may lead to the loss of valuable biological material, unintended selection of resilient cell populations, or introduce contamination.

\subsection{Advanced and special culture procedures}

As the cell culture field is constantly evolving and advancing, it is important to support this with a continuous laboratory training plan. For example, the use of hPSCs as a source for cells differentiated further to a specific cell type has increased exponentially in many fields and requires very specific training. Colony identification and selection, quality of colonies, colony examination, confluence and passage, differentiation techniques, etc., require special attention and training when manipulating iPSCs (for a review, see Pamies et al., 2017).

Since there are diverse protocols and technologies emerging not only for stem cell cultures but also many other cell types or new differentiation protocols (organotypic cultures or MPS), it is very difficult to find consensus between protocols and achieve standardization among labs. Specifically, comprehensive training for research groups within a multinational project consortium is of significant value to increase robustness and reproducibility of methods and to strictly adhere to agreed protocols or SOPs to facilitate/enable comparisons of research findings within the consortium (Pamies et al., 2017).

Special attention is required when using MPS, which combine biology and material sciences (microfabrication), among others, and represent a challenge to foster interdisciplinary research and training. Training that facilitates crosstalk between different fields (such as workshops or informational talks) can improve interdisciplinary background, facilitate time optimization, and avoid waste of time and money.

\subsection{Documentation, safety, legal and ethical training}

Training programs and education should be formally documented for all members of the staff to monitor progress, plan future training, and identify the lack of adequate practices. The latter can be achieved through periodical laboratory inspections.

Workers require sufficient understanding of laws and regulations specific to the cell material (both animal and human origin) they are using. Moreover, it is important to make sure that training in such issues is provided before starting work. For certain applications, including product manufacturing and testing, and processing of cells and tissues for clinical use, training must be formally recorded and reviewed. Moreover, the use of a human cell source, such as hPSCs or primary cultures, requires special attention to the ethical aspects and the biohazard risks associated with this specific cell culture work; thus, specific training should be done on these two aspects before starting a new work position (Pamies et al., 2017, 2018).

In addition, training on documentation is recommended for good cell culture practice (Principle 3). Knowing how to document and archive data and results, the use of equipment, and how to handle the documents not only could help identify problems, but also avoid breaching ethical contracts or laws. In cell cultures derived from patient samples, for example, not knowing the restrictions contained in the informed consent signed by the donor and the limitations of the use of the data could lead to legal complaint to the laboratory or operator.

\section{Conclusions}

The development of the seminal GCCP guidance document (Coecke et al., 2005) has strongly contributed to a higher quality assurance of cell culture work. However, novel technologies have appeared since the original publication. During recent years, the GCCP collaboration has organized several activities to collect 
Tab. 10: Examples of culture techniques, procedures, and regulations that should be included in a cell culture laboratory training program

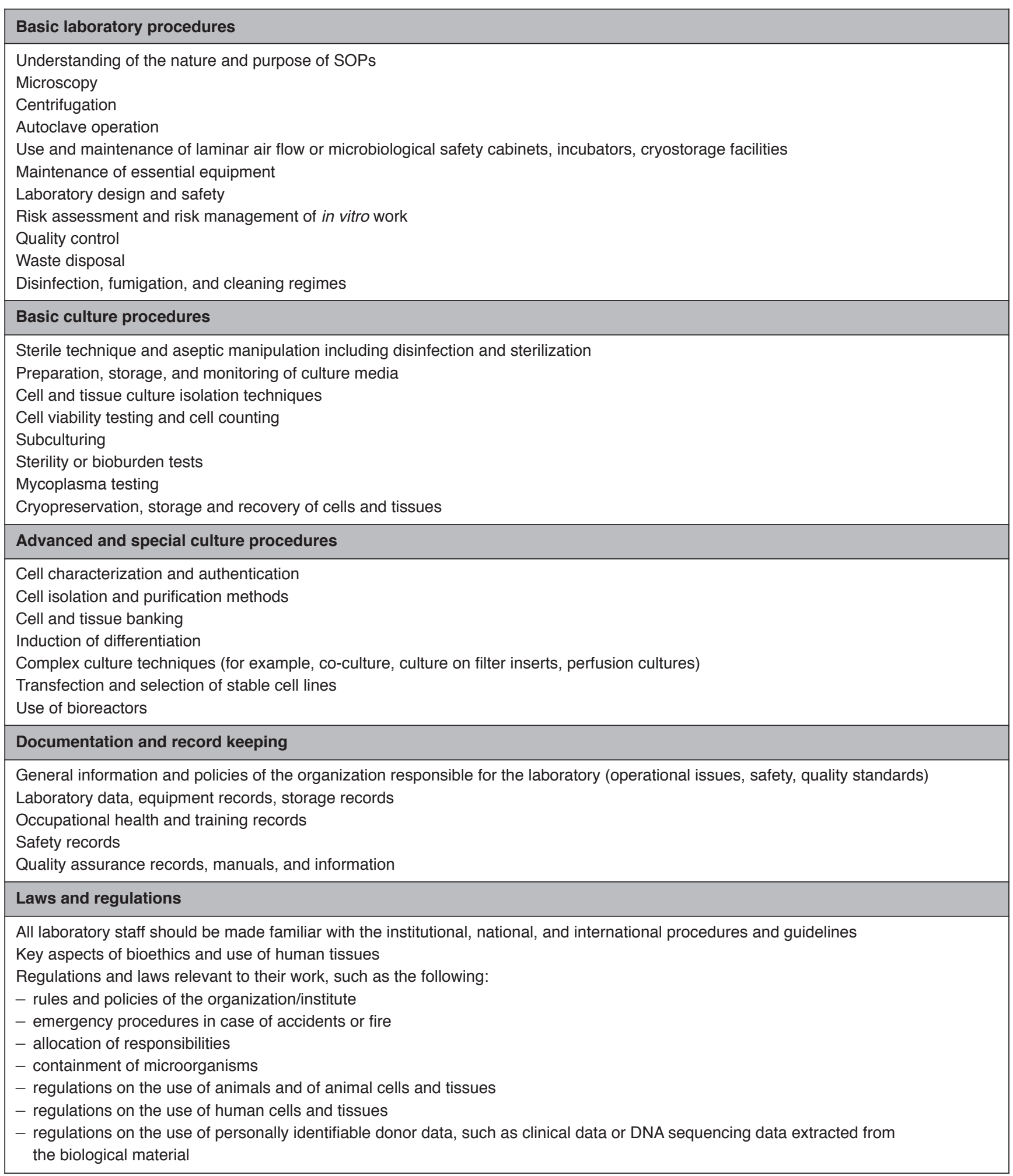


information about the most relevant advances in cell culture and their specific consideration in the GCCP context. In this manuscript, we have updated the previously published version of the GCCP document (Coecke et al., 2005) with information on new cell culture technologies and cross-referenced applicable sections of the OECD GIVIMP document. Techniques such as iPSCs, organotypic cultures, microfluidics, organ-on-a-chip systems, and primary cells have been included and discussed in detail. In this document, the importance of the incorporation of the six GCCP principles to obtain good-quality data has been described, with the intention to provide a broad-ranging guide for cell cultures. Since cell culture is an evolving field, the GCCP guidelines must be considered a living document and will require further updates to incorporate scientific discoveries and novel cell culture techniques.

This document does not intend to impose detailed procedures, but rather aims to advise and explain the possible consequences of not taking into account specific steps or aspects. The objective of the document is to educate new scientists working in cell culture and update scientists who have been working in the field for some time.

Acceptance among different scientists in the field is key for an optimal implementation of the guidance document. Thus, the manuscript was initially developed and approved by the GCCP Steering Committee (Pamies et al., 2020). In order to promote the large-scale implementation of the principles, a variety of relevant stakeholders - ranging from editors of journals and scientific societies to regulatory and funding agencies involved in cell culture - were approached and requested to provide feedback on the manuscript. Through a consensus process, this feedback was incorporated into the manuscript by the Steering Committee. Moreover, to make good practice recommendations available, proactive dissemination and education will be two of the focus areas of the ongoing GCCP collaboration. This includes discussion with editors of journals to require quality assurance prior to publication of manuscripts.

In conclusion, this document is a comprehensive guidance document that has received broad-ranging input from many fields and provides the necessary information to promote the generation of good-quality reproducible data, facilitate inter-laboratory comparability, and to help overcome possible problems intrinsic to cell culture work.

\section{References}

Adler, S., Allsopp, T., Bremer, S. et al. (2007). hESC technology for toxicology and drug development: Summary of current status and recommendations for best practice and standardization. The Report and Recommendations of an ECVAM Workshop. http://ecvam.jrc.it/publication/hESC_\%20010711.pdf

Aguilar, P. S., Baylies, M. K., Fleissner, A. et al. (2013). Genetic basis of cell-cell fusion mechanisms. Trends Genet 29, 427437. doi:10.1016/j.tig.2013.01.011

Al-Ani, A., Toms, D., Kondro, D. et al. (2018). Oxygenation in cell culture: Critical parameters for reproducibility are routinely not reported. PLoS One 13, e0204269. doi:10.1371/journal. pone. 0204269
Andrews, P. W., Baker, D., Benvinisty, N. et al. (2015). Points to consider in the development of seed stocks of pluripotent stem cells for clinical applications: International stem cell banking initiative (ISCBI). Regen Med 10, Suppl 2, 1-44. doi:10.2217/ rme.14.93

Angel, S., von Briesen, H., Oh, Y.-J. et al. (2016). Toward optimal cryopreservation and storage for achievement of high cell recovery and maintenance of cell viability and $\mathrm{T}$ cell functionality. Biopreserv Biobank 14, 539-547. doi:10.1089/ bio. 2016.0046

Assou, S., Bouckenheimer, J., De Vos, J. (2018). Concise review: Assessing the genome integrity of human induced pluripotent stem cells: What quality control metrics? Stem Cells 36, 814821. doi:10.1002/stem.2797

Awan, M., Buriak, I., Fleck, R. et al. (2020). Dimethyl sulfoxide: A central player since the dawn of cryobiology, is efficacy balanced by toxicity? Regen Med 15, 1463-1491. doi:10.2217/ rme-2019-0145

Babic, Z., Capes-Davis, A., Martone, M. E. et al. (2019). Incidences of problematic cell lines are lower in papers that use RRIDS to identify cell lines. Elife 8, e41676. doi:10.7554/ eLife. 41676

Bairoch A. (2018). The Cellosaurus, a cell-line knowledge resource. J Biomol Tech 29, 25-38. doi:10.7171/jbt.18-2902-002

Baker, M. (2016a). Is there a reproducibility crisis? Nature 533, 452-454. doi:10.1038/533452a

Baker, M. (2016b). Reproducibility: Respect your cells! Nature 537, 433-435. doi:10.1038/537433a

Baumstummler, A., Chollet, R., Meder, H. et al. (2010). Detection of microbial contaminants in mammalian cell cultures using a new fluorescence-based staining method. Lett Appl Microbiol 51, 671-677. doi:10.1111/j.1472-765X.2010.02952.x

Baust, J. M., Campbell, L. H. and Harbell, J. W. (2017). Best practices for cryopreserving, thawing, recovering, and assessing cells. In Vitro Cell Dev Biol Anim 53, 855-871. doi:10.1007/s11626-017-0201-y

Ben-David, U., Siranosian, B., Ha, G. et al. (2018). Genetic and transcriptional evolution alters cancer cell line drug response. Nature 560, 325-330. doi:10.1038/s41586-018-0409-3

Berkhout, B. (2018). RNAi-mediated antiviral immunity in mammals. Curr Opin Virol 32, 9-14. doi:10.1016/j.coviro. 2018.07.008

Berthois, Y., Katzenellenbogen, J. A. and Katzenellenbogen, B. S. (1986). Phenol red in tissue culture media is a weak estrogen: Implications concerning the study of estrogen-responsive cells in culture. Proc Natl Acad Sci U S A 83, 2496-500. doi:10.1073/pnas.83.8.2496

Blazquez-Prunera, A., Diez, J. M., Gajardo, R. et al. (2017). Human mesenchymal stem cells maintain their phenotype, multipotentiality, and genetic stability when cultured using a defined xeno-free human plasma fraction. Stem Cell Res Ther 8, 103. doi:10.1186/s13287-017-0552-Z

Bonnier, F., Keating, M. E., Wrobel, T. P. et al. (2015). Cell viability assessment using the Alamar blue assay: A comparison of 2D and 3D cell culture models. Toxicol In Vitro 29, 124-131. doi:10.1016/j.tiv.2014.09.014 
Bredenoord, A. L., Clevers, H. and Knoblich, J. A. (2017). Human tissues in a dish: The research and ethical implications of organoid technology. Science 355, eaaf9414. doi:10.1126/ science.aaf9414

Brunner, D., Frank, J., Appl, H. et al. (2010). Serum-free cell culture: The serum-free media interactive online database. ALTEX 27, 53-62. doi:10.14573/altex.2010.1.53

Campisi, J. and di Fagagna, F. D. (2007). Cellular senescence: When bad things happen to good cells. Nat Rev Mol Cell Biol 8, 729-740. doi:10.1038/nrm2233

Capes-Davis, A., Theodosopoulos, G., Atkin, I. et al. (2010). Check your cultures! A list of cross-contaminated or misidentified cell lines. Int J Cancer 127, 1-8. doi:10.1002/ ijc. 25242

Capes-Davis, A., Reid, Y. A., Kline, M. C. et al. (2013). Match criteria for human cell line authentication: Where do we draw the line? Int J Cancer 132, 2510-2519. doi:10.1002/ijc.27931

Carragher, N., Piccinini, F., Tesei, A. et al. (2018). Concerns, challenges and promises of high-content analysis of 3D cellular models. Nat Rev Drug Discov 17, 607-608. doi:10.1038/ nrd.2018.99

Casadevall, A., Steen, R. G. and Fang, F. C. (2014). Sources of error in the retracted scientific literature. FASEB J 28, 38473855. doi:10.1096/fj.14-256735

Chan, K. K., Wu, S. M., Nissom, P. M. et al. (2008). Generation of high-level stable transgene expressing human embryonic stem cell lines using Chinese hamster elongation factor-1 alpha promoter system. Stem Cells Dev 17, 825-836. doi:10.1089/ scd.2008.0233

Coecke, S., Balls, M., Bowe, G. et al. (2005). Guidance on Good Cell Culture Practice - A report of the second ECVAM task force on Good Cell Culture Practice. Altern Lab Anim 33, 261287. doi:10.1177/026119290503300313

Coté, R. (2001). Assessing and controlling microbial contamination in cell cultures. Curr Protoc Cell Biol, Chapter 1, Unit 1.5. doi:10.1002/0471143030.cb0105s01

Daily, K., Sui, S. J. H., Schriml, L. M. et al. (2017). Molecular, phenotypic, and sample-associated data to describe pluripotent stem cell lines and derivatives. Sci Data 4, 170030. doi:10.1038/sdata.2017.30

Darou, S., Henn, A., Alm, K. et al. (2019). Abstract 2157: Eliminating edge effect in 96 -well plates by controlling thermal conditions during cell plating. Cancer Res 79, 2157. doi: 10.1158/1538-7445.AM2019-2157

Davoli, T. and de Lange, T. (2011). The causes and consequences of polyploidy in normal development and cancer. Annu Rev Cell Dev Biol 27, 585-610. doi:10.1146/annurevcellbio-092910-154234

Dirks, W. G., MacLeod, R. A., Nakamura, Y. et al. (2009). Cell line cross-contamination initiative: An interactive reference database of STR profiles covering common cancer cell lines. Int J Cancer 126, 303-304. doi:10.1002/ijc.24999

Drexler, H. G. and Uphoff, C. C. (2002). Mycoplasma contamination of cell cultures: Incidence, sources, effects, detection, elimination, prevention. Cytotechnology 39, 75-90. doi:10.1023/A:1022913015916
Duval, K., Grover, H., Han, L. H. et al. (2017). Modeling physiological events in 2D vs. 3D cell culture. Physiology 32, 266277. doi:10.1152/physiol.00036.2016

EC (2007). Regulation (EC) No 1394/2007 of the European Parliament and of the Council of 13 November 2007 on advanced therapy medicinal products and amending Directive 2001/83/ EC and Regulation (EC) No 726/2004. OJ L324, 121-137. http://data.europa.eu/eli/reg/2007/1394/oj

Eskes, C., Bostrom, A. C., Bowe, G. et al. (2017). Good cell culture practices \& in vitro toxicology. Toxicol In Vitro 45, 272277. doi:10.1016/j.tiv.2017.04.022

EU (1995). Directive 95/46/EC of the European Parliament and of the Council of 24 October 1995 on the protection of individuals with regard to the processing of personal data and on the free movement of such data. OJ L 281, 31-50. http://data. europa.eu/eli/dir/1995/46/oj

EU (2001a). Directive 2001/18/EC of the European Parliament and of the Council of 12 March 2001 on the deliberate release into the environment of genetically modified organisms and repealing Council Directive 90/220/EEC - Commission Declaration. OJ L 106, 1-39. http://data.europa.eu/eli/dir/2001/18/ oj

EU (2001b). Regulation (EC) No 1394/2007 of the European Parliament and of the Council of 13 November 2007 on advanced therapy medicinal products and amending Directive 2001/83/EC and Regulation (EC) No 726/2004. OJ L 324, 121-137. http://data.europa.eu/eli/reg/2007/1394/oj

EU (2004). Directive 2004/23/EC of the European Parliament and of the Council on setting standards of quality and safety for the donation, procurement, testing, processing, preservation, storage and distribution of human tissues and cells. $O J L$ 102, 48-58. http://data.europa.eu/eli/dir/2004/23/oj

EU (2006a). Commission Directive 2006/17/EC of 8 February 2006 implementing Directive 2004/23/EC of the European Parliament and of the Council as regards certain technical requirements for the donation, procurement and testing of human tissues and cells. OJ L 38, 40-52. http://data.europa.eu/eli/ $\operatorname{dir} / 2006 / 17 /$ oj

EU (2006b). Technical Annex 2: Commission Directive 2006/86/ EC of 24 October 2006 implementing Directive 2004/23/ EC of the European Parliament and of the Council as regards traceability requirements, notification of serious adverse reactions and events and certain technical requirements for the coding, processing, preservation, storage and distribution of human tissues and cells. OJ L 294, 41-43. https:// eur-lex.europa.eu/legal-content/EN/TXT/PDF/?uri=CELEX: 32006L0086\&qid $=1594671604632 \&$ from $=\mathrm{EN}$

EU (2006c). Technical Annex 1: Commission Directive 2006/17/ EC of 8 February 2006 implementing Directive 2004/23/EC of the European Parliament and of the Council as regards certain technical requirements for the donation, procurement and testing of human tissues and cells. OJ L 38, 43-44. https:// eur-lex.europa.eu/legal-content/EN/TXT/PDF/?uri=CELEX: 32006L0017\&qid $=1594672077891 \&$ from $=\mathrm{EN}$

EU (2009). Directive 2009/41/EC of the European Parliament and of the Council of 6 May 2009 on the contained use of ge- 
netically modified micro-organisms. OJ L 125, 75-97. http:// data.europa.eu/eli/dir/2009/41/oj

EU (2010). Directive 2010/63/EU of the European Parliament and of the Council of 22 September 2010 on the protection of animals used for scientific purposes. OJ L 276, 33-79. http:// data.europa.eu/eli/dir/2010/63/oj

EU (2012). Commission Directive 2012/39/EU of 26 November 2012 amending Directive 2006/17/EC as regards certain technical requirements for the testing of human tissues and cells. OJ L 327, 24-25. http://data.europa.eu/eli/dir/2012/39/oj

EU (2014). Directive 2014/68/EU of the European Parliament and of the Council of May 2014 on the harmonisation of the laws of the Member States relating to the making available on the market of pressure equipment. OJ L 189, 164-259. http:/ data.europa.eu/eli/dir/2014/68/oj

Falsig, J., Julius, C., Margalith, I. et al. (2008). A versatile prion replication assay in organotypic brain slices. Nat Neurosci 11, 109-117. doi:10.1038/nn2028

FDA (2001). 21CFR1271. Human Cells, Tissues, and Cellular and Tissue-Based Products. Updated 2015.

FDA (2010). CBER Annual Report: Innovative Technology Advancing Public Health.

FDA (2013). 21CFR610. General Biological Products Standards. US Food and Drug Administration; Rockville, MD.

FDA (2015a). 21CFR600. Biological Products: General.

FDA (2015b). 21CFR312. Investigational New Drug Application. Updated 2015.

FDA (2015c). 21CFR210. Current Good Manufacturing Practice in Manufacturing, Processing, Packing, or Holding of Drugs; General. Updated 2015.

FDA (2019a). 21CFR630. Requirements for Blood and Blood Components Intended for Transfusion or for Further Manufacturing Use. Code of Federal Regulations Title 21, Volume 7.

FDA (2019b). 21CFR606. Current Good Manufacturing Practice for Blood and Blood Components. Code of Federal Regulations Title 21, Volume 7.

Foty, R. (2011). A simple hanging drop cell culture protocol for generation of 3D spheroids. J Vis Exp 51, e2720. doi:10. 3791/2720

Fountain, D., Ralston, M., Higgins, N. et al. (1997). Liquid nitrogen freezers: A potential source of microbial contamination of hematopoietic stem cell components. Transfusion 37, 585591. doi:10.1046/j.1537-2995.1997.37697335152.x

Freedman, L. P., Gibson, M. C., Wisman, R. et al. (2015). The culture of cell culture practices and authentication Results from a 2015 survey. Biotechniques 59, 189-190, 192. doi: $10.2144 / 000114344$

Freshney, R. I. (2016). Culture of Animal Cells: A Manual of Basic Technique and Specialized Applications. $7^{\text {th }}$ edition. John Wiley \& Sons, Inc.

Frommer, W., Archer, L., Boon, B. et al. (1993). Safe biotechnology (5). Recommendations for safe work with animal and human cell cultures concerning potential human pathogens. Appl Microbiol Biotechnol 39, 141-147. doi:10.1007/ bf00228597

Geraghty, R. J., Capes-Davis, A., Davis, J. M. et al. (2014).
Guidelines for the use of cell lines in biomedical research. Br J Cancer 111, 1021-1046. doi:10.1038/bjc.2014.166

Gstraunthaler, G. (2003). Alternatives to the use of fetal bovine serum: Serum-free cell culture. ALTEX 20, 275-281. doi:10.14573/altex.2003.4.257

Gilbert, D. F., Mofrad, S. A., Friedrich, O. et al. (2019). Proliferation characteristics of cells cultured under periodic versus static conditions. Cytotechnology 71, 443-452. doi:10.1007/ s10616-018-0263-z

Grout, B. W. and Morris, G. J. (2009). Contaminated liquid nitrogen vapour as a risk factor in pathogen transfer. Theriogenology 71, 1079-1082. doi:10.1016/j.theriogenology.2008.12.011

Hartung, T., Balls, M., Bardouille, C. et al. (2002). Good Cell Culture Practice. ECVAM Good Cell Culture Practice task force report 1. Altern Lab Anim 30, 407-414. doi:10. 1177/026119290203000404

Hartung, T., Blaauboer, B. and Leist, M. (2009). Food for thought ... on education in alternative methods in toxicology. ALTEX 26, 255-263. doi:10.14573/altex.2009.4.255

Hawkins, K. E., Sharp, T. V. and McKay, T. R. (2013). The role of hypoxia in stem cell potency and differentiation. Regen Med 8, 771-782. doi:10.2217/rme.13.71

Hayflick, L. (1965). The limited in vitro lifetime of human diploid cell strains. Exp Cell Res 37, 614-636. doi:10.1016/00144827(65)90211-9

Hendriks, W. T., Warren, C. R. and Cowan, C. A. (2016). Genome editing in human pluripotent stem cells: Approaches, pitfalls, and solutions. Cell Stem Cell 18, 53-65. doi:10.1016/j. stem.2015.12.002

Hernandez, J. M. and Podbilewicz, B. (2017). The hallmarks of cell-cell fusion. Development 144, 4481-4495. doi:10.1242/ dev. 155523

International Stem Cell Banking Initiative (2009). Consensus guidance for banking and supply of human embryonic stem cell lines for research purposes. Stem Cell Rev Rep 5, 301-314. doi:10.1007/s12015-009-9085-x

International Stem Cell Initiative, Amps, K., Andrews, P. W. et al. (2011). Screening ethnically diverse human embryonic stem cells identifies a chromosome 20 minimal amplicon conferring growth advantage. Nat Biotechnol 29, 1132-1144. doi:10.1038/nbt.2051

International Stem Cell Initiative (2018). Assessment of established techniques to determine developmental and malignant potential of human pluripotent stem cells. Nat Comm 9, 1925. doi:10.1038/s41467-018-04011-3

Ivanovic, Z. (2009). Hypoxia or in situ normoxia: The stem coll paradigm. J Cell Physiol 219, 271-275. doi:10.1002/jcp.21690

Jacobs, K., Zambelli, F., Mertzanidou, A. et al. (2016). Higherdensity culture in human embryonic stem cells results in DNA damage and genome instability. Stem Cell Reports 6, 330-341. doi:10.1016/j.stemcr.2016.01.015

Jez, M., Rozman, P., Ivanovic, Z. et al. (2015). Concise review: The role of oxygen in hematopoietic stem cell physiology. $J$ Cell Physiol 230, 1999-2005. doi:10.1002/jcp.24953

Keeley, T. P. and Mann, G. E. (2019). Defining physiological normoxia for improved translation of cell physiology to animal 
models and humans. Physiol Rev 99, 161-234. doi:10.1152/ physrev.00041.2017

Kleensang, A., Vantangoli, M. M., Odwin-DaCosta, S. et al. (2016). Erratum: Genetic variability in a frozen batch of MCF-7 cells invisible in routine authentication affecting cell function. Sci Rep 6, 33011. doi:10.1038/srep33011

Krebs, A., Waldmann, T., Wilks, M. F. et al. (2019). Template for the description of cell-based toxicological test methods to allow evaluation and regulatory use of the data. ALTEX 36, 682-699. doi:10.14573/altex.1909271

Krejciova, Z., Alibhai, J., Zhao, C. et al. (2017). Human stem cell-derived astrocytes replicate human prions in a PRNP genotype-dependent manner. J Exp Med 214, 3481-3495. doi:10.1084/jem.20161547

Kurtz, A., Seltmann, S., Bairoch, A. et al. (2018). A standard nomenclature for referencing and authentication of pluripotent stem cells. Stem Cell Reports 10, 1-6. doi:10.1016/j.stemcr. 2017.12.002

Lanbeck, P. and Paulsen, O. (1995). Cytotoxic effects of four antibiotics on endothelial cells. Pharmacol Toxicol 77, 365-370. doi:10.1111/j.1600-0773.1995.tb01043.x

Lanbeck, P. and Paulsen, O. (2001). Short-term effects of four antibiotics on DNA synthesis in endothelial cells. Pharmacol Toxicol 88, 204-208. doi:10.1034/j.1600-0773. 2001.d01-105.x

Lawson, V. A., Vella, L. J., Stewart, J. D. et al. (2008). Mouse-adapted sporadic human Creutzfeldt-Jakob disease prions propagate in cell culture. Int J Biochem Cell Biol 40, 2793 2801. doi:10.1016/j.biocel.2008.05.024

Lincoln, C. K. and Gabridge, M. G. (1998). Cell culture contamination: Sources, consequences, prevention, and elimination. Methods Cell Biol 57, 49-65. doi:10.1016/S0091-679X (08)61571-X

Liu, Y., Mi, Y., Mueller, T. et al. (2019). Multi-omic measurements of heterogeneity in HeLa cells across laboratories. Nat Biotechnol 37, 314-322. doi:10.1038/s41587-019-0037-y

Lloyd, G., Bowen, E. T. W., Jones, N. et al. (1984). HFRS outbreak associated with laboratory rats in UK. Lancet 1, 1175-1176.

Luong, M. X., Auerbach, J., Crook, J. M. et al. (2011). A call for standardized naming and reporting of human ESC and iPSC lines. Cell Stem Cell 8, 357-359. doi:10.1016/j. stem.2011.03.002

Mabry, K. M., Payne, S. Z. and Anseth, K. S. (2016). Microarray analyses to quantify advantages of $2 \mathrm{D}$ and $3 \mathrm{D}$ hydrogel culture systems in maintaining the native valvular interstitial cell phenotype. Biomaterials 74, 31-41. doi:10.1016/j .biomaterials.2015.09.035

MacLeod, R. A. F. and Drexler, H. G. (2005). Cytogenetic analysis of cell lines. In C. D. Helgason and C. L. Miller (eds.), Basic Cell Culture Protocols. Methods in Molecular Biology ${ }^{\mathrm{TM}}$ 290. Humana Press. doi:10.1385/1-59259-838-2:051

Mahy, B. W., Dykewicz, C., Fisher-Hoch, S. et al. (1991). Virus zoonoses and their potential for contamination of cell cultures. Dev Biol Stand 75, 183-189.

Majmundar, A. J., Wong, W. J., Simon, M. C. (2010). Hypox- ia-inducible factors and the response to hypoxic stress. Mol Cell 40, 294-309. doi:10.1016/j.molcel.2010.09.022

Marx, U., Andersson, T. B., Bahinski, A. et al. (2016). Biologyinspired microphysiological system approaches to solve the prediction dilemma of substance testing using animals. ALTEX 33, 272-321. doi:10.14573/altex.1603161

Marx, U., Akabane, T., Andersson, T. B. et al. (2020). Biologyinspired microphysiological systems to advance medicines for patient benefit and animal welfare. ALTEX 37, 365-394. doi:10.14573/altex.2001241

Masters, J. R. and Stacey, G. N. (2007). Changing medium and passaging cell lines. Nat Protoc 2, 2276-2284. doi:10.1038/ nprot.2007.319

Meza-Zepeda, L. A., Noer, A., Dahl, J. A. et al. (2008). High-resolution analysis of genetic stability of human adipose tissue stem cells cultured to senescence. J Cell Mol Med 12, 553-563. doi:10.1111/j.1582-4934.2007.00146.x

Morris, G. J. (2005). The origin, ultrastructure, and microbiology of the sediment accumulating in liquid nitrogen storage vessels. Cryobiology 50, 231-238. doi:10.1016/j.cryobiol. 2005.01.005

Mount, S., Kanda, P., Parent, S. et al. (2019). Physiologic expansion of human heart-derived cells enhances therapeutic repair of injured myocardium. Stem Cell Res Ther 10, 316. doi:10.1186/s13287-019-1418-3

Munafo, M. R., Nosek, B. A., Bishop, D. V. M. et al. (2017). A manifesto for reproducible science. Nat Hum Behav 1, 0021. doi:10.1038/s41562-016-0021

NCCUSL - National Conference of Commissioners on Uniform State Laws (2006). Revised Uniform Anatomical Gift Act (2006). Uniform Law Commission. https://bit.ly/3IN4lkE

Nelson Rees, W. A., Daniels, D. W. and Flandermeyer, R. R. (1981). Cross-contamination of cells in culture. Science 212, 446-452. doi:10.1126/science.6451928

Nesterenko, Y., Dolde, X., Leist, M. et al. (2020). Strategy to replace animal-derived ECM by a modular and highly defined matrix. ALTEX 37, 482-489. doi:10.14573/altex.2003181

Nims, R. W. and Harbell, J. W. (2017). Best practices for the use and evaluation of animal serum as a component of cell culture medium. In Vitro Cell Dev Biol Anim 53, 682-690. doi:10.1007/s11626-017-0184-8

OECD (2018). Guidance Document on Good In Vitro Method Practices (GIVIMP). OECD Series on Testing and Assessment, No. 286. OECD Publishing, Paris. doi:10.1787/ 9789264304796-en

Ogle, B., Cascalho, M., Platt, J. (2005). Biological implications of cell fusion. Nat Rev Mol Cell Biol 6, 567-575. doi:10.1038/ nrm1678

O'Shea, O., Steeg, R., Chapman, C. et al. (2020). Development and implementation of large-scale quality control for the European bank for induced pluripotent stem cells. Stem Cell Res 45, 101773. doi:10.1016/j.scr.2020.101773

Ottosen, L. D. M., Hindkjaer, J., Husth, M. et al. (2006). Observations on intrauterine oxygen tension measured by fibreoptic microsensors. Reprod Biomed Online 13, 380-385. doi: 10.1016/S1472-6483(10)61443-5 
Pamies, D., Vicente-Salar, N., Sogorb, M. A. et al. (2013). The effect of $\mathrm{CO}_{2}$ concentration in neuroectoderm commitment of mouse embryonic stem cells. J Histotechnol 36, 11-12. doi:10. 1179/2046023612Y.0000000018

Pamies, D., Bal-Price, A., Simeonov, A. et al. (2017). Good Cell Culture Practice for stem cells and stem-cell-derived models. ALTEX 34, 95-132. doi:10.14573/altex.1607121

Pamies, D., Bal-Price, A., Chesne, C. et al. (2018). Advanced Good Cell Culture Practice for human primary, stem cellderived and organoid models as well as microphysiological systems. ALTEX 35, 353-378. doi:10.14573/altex.1710081

Pamies, D., Leist, M., Coecke, S. et al. (2020). Good cell and tissue culture practice 2.0 (GCCP 2.0) - Draft for stakeholder discussion and call for action. ALTEX 37, 490-492. doi:10.14573/altex.2007091

Petricciani, J., Hayakawa, T., Stacey, G. et al. (2017). Scientific considerations for the regulatory evaluation of cell therapy products. Biologicals 50, 20-26. doi:10.1016/j. biologicals.2017.08.011

Pirnay, J. P., Baudoux, E., Cornu, O. et al. (2015). Access to human tissues for research and product development: From EU regulation to alarming legal developments in Belgium. EMBO Rep 16, 557-562. doi:10.15252/embr.201540070

Pistollato, F., Bremer-Hoffmann, S., Healy, L. et al. (2012). Standardization of pluripotent stem cell cultures for toxicity testing. Expert Opin Drug Metab Toxicol 8, 239-257. doi:10.1517 $/ 17425255.2012 .639763$

Price, P. J. (2017). Best practices for media selection for mammalian cells. In Vitro Cell Dev Biol Anim 53, 673-681. doi:10.1007/s11626-017-0186-6

Rebuzzini, P., Zuccotti, M., Redi, C. A. et al. (2016). Achilles' heel of pluripotent stem cells: Genetic, genomic and epigenetic variations during prolonged culture. Cell Mol Life Sci 73, 2453-2466. doi:10.1007/s00018-016-2171-8

Reid, Y. A. (2017). Best practices for naming, receiving, and managing cells in culture. In Vitro Cell Dev Biol Anim 53, 761774. doi:10.1007/s11626-017-0199-1

Russell, W. M. S. and Burch, R. L. (1959). The Principles of Humane Experimental Technique. London, UK: Methuen.

SaBTO (2014). Donation of Starting Material for Cell-Based Advanced Therapies: A SaBTO Review. Advisory Committee on the Safety of Blood Tissues and Organs. Department of Health and Social Care.

Scarfe, L., Brillant, N., Kumar, J. D. et al. (2017). Preclinical imaging methods for assessing the safety and efficacy of regenerative medicine therapies. NPJ Regen Med 2, 28. doi:10.1038/ s41536-017-0029-9

Scarritt, M. E., Pashos, N. C. and Bunnell, B. A. (2015). A review of cellularization strategies for tissue engineering of whole organs. Front Bioeng Biotechnol 3, 43. doi:10.3389/ fbioe. 2015.00043

Schaeffer, W. I. (1990). Terminology associated with cell, tissue and organ-culture, molecular-biology and molecular-genetics. In Vitro Cell Dev Biol 26, 97-101. doi:10.1007/BF02624162

Schildknecht, S., Karreman, C., Poltl, D. et al. (2013). Genera- tion of genetically-modified human differentiated cells for toxicological tests and the study of neurodegenerative diseases. ALTEX 30, 427-444. doi:10.14573/altex.2013.4.427

Scholz, D., Chernyshova, Y., Uckert, A. K. et al. (2018). Reduced $\mathrm{A} \beta$ secretion by human neurons under conditions of strongly increased bace activity. J Neurochem 147, 256-274. doi:10.1111/jnc. 14467

Seltmann, S., Lekschas, F., Mueller, R. et al. (2016). hPSCreg The human pluripotent stem cell registry. Nucleic Acids Res 44, D757-763. doi:10.1093/nar/gkv963

Serra, M., Brito, C., Correia, C. et al. (2012). Process engineering of human pluripotent stem cells for clinical application. Trends Biotechnol 30, 350-359. doi:10.1016/j.tibtech.2012.03.003

Shay, J. W. and Wright, W. E. (2000). Hayflick, his limit, and cellular ageing. Nat Rev Mol Cell Biol 1, 72-76. doi:10. $1038 / 35036093$

Shimoni, Y., Forsyth, T., Srinivasan, V. et al. (2018). Reducing Variability in Cell-Specific Productivity in Perfusion Culture: A Case Study. BioProcess International. https://bioprocessintl. com/upstream-processing/perfusion-cell-culture/reducingvariability-in-cell-specific-productivity-in-perfusion-culturea-case-study/

Stacey, G. N. and Hartung, T. (2006). Availability, standardization and safety of human cells and tissues for drug screening and testing. In U. Marx and V. Sandig (eds.), Drug Testing In Vitro - Breakthroughs and Trends in Cell Culture Technology (231-250, Chapter 9).

Stacey, G. N. (2007). Risk assessment of cell culture procedures. In G. Stacey and J. Davis (eds.), Medicines from Animal Cell Culture (567-587, Chapter 31). Wiley Online Library. doi:10.1002/9780470723791.ch31

Stacey, G. N. (2011). Cell culture contamination. In I. Cree (ed.), Cancer Cell Culture. Methods Mol Biol 731, 79-91. doi:10.1007/978-1-61779-080-5_7

Stacey, G. N., Crook, J. M., Heī, D. et al. (2013). Banking human induced pluripotent stem cells: Lessons learned from embryonic stem cells? Cell Stem Cell 13, 385-388. doi:10.1016/j.stem.2013.09.007

Stacey, G. N., Coecke, S., Price, A. B. et al. (2016a). Ensuring the quality of stem cell-derived in vitro models for toxicity testing. Adv Exp Med Biol 856, 259-297. doi:10.1007/978-3319-33826-2 11

Stacey, G. N., Healy., L., Man, J. et al. (2016b). Fundamental points to consider in the cryopreservation and shipment of cells for human application. In C. J. Connon (ed.), Bioprocessing for Cell Based Therapies (167-186, Chapter 6). Wiley Online Library. doi:10.1002/9781118743362.ch6

Stacey, G. N. and Hawkins, J. R. (2017). Cell lines: Applications and biosafety. In D. P. Wooley and K. B. Byers (eds.), Biological Safety, Principles and Practices (299-325, Chapter 14). $5^{\text {th }}$ edition. Wiley Online Library. doi:10.1128/9781555819637. ch14

Stepanenko, A. A. and Heng, H. H. (2017). Transient and stable vector transfection: Pitfalls, off-target effects, artifacts. Mutat Res 773, 91-103. doi:10.1016/j.mrrev.2017.05.002 
Swim, H. E. and Parker, R. F. (1957). Culture characteristics of human fibroblasts propagated serially. Am J Hyg 66, 235-243. doi:10.1093/oxfordjournals.aje.a119897

Tedder, R. S., Zuckerman, M. A., Goldstone, A. H. et al. (1995). Hepatitis B transmission from contaminated cryopreservation tank. Lancet 346, 137-140. doi:10.1016/s01406736(95)91207-x

Tigges, J., Bielec, K., Brockerhoff, G. et al. (2021). Academic application of Good Cell Culture Practice for induced pluripotent stem cells. ALTEX 38, 595-614. doi:10.14573/altex.2101221

UK (2004). Human Tissue Act 2004. http://www.legislation.gov. uk/ukpga/2004/30/pdfs/ukpga_20040030_en.pdf

Uphoff, C. C., Denkmann, S. A., Steube, K. G. et al. (2010). Detection of EBV, HBV, HCV, HIV-1, HTLV-I and -II, and SMRV in human and other primate cell lines. J Biomed Biotechnol 2010, 904767. doi:10.1155/2010/904767

Uphoff, C. C., Pommerenke, C., Denkmann, S. A. et al. (2019). Screening human cell lines for viral infections applying RNASeq data analysis. PLoSOne 14, e0210404. doi:10.1371/journal. pone. 0210404

van der Valk, J., Bieback, K., Buta, C. et al. (2018). Fetal bovine serum (FBS): Past - Present - Future. ALTEX 35, 99-118. doi:10.14573/altex.1705101

Villa-Diaz, L. G., Ross, A. M., Lahann, J. et al. (2013). Concise review: The evolution of human pluripotent stem cell culture: From feeder cells to synthetic coatings. Stem Cells 31, 1-7. doi: 10.1002/stem. 1260

Volpato, V., Smith, J., Sandor, C. et al. (2018). Reproducibility of molecular phenotypes after long-term differentiation to human iPSC-derived neurons: A multi-site omics study. Stem Cell Reports 11, 897-911. doi:10.1016/j.stemcr.2018.08.013

Vracko, R., McFarland, B. H. and Pecoraro, R. E. (1983). Seeding efficiency, plating efficiency, and population doublings of human skin fibroblastlike cells: Results of replicate testing. In Vitro 19, 504-514. doi:10.1007/bf02619598

Waymouth, C. (1970). Osmolality of mammalian blood and of media for culture of mammalian cells. In Vitro 6, 109-127. doi: 10.1007/bf02616113

Wenger, R. H., Kurtcuoglu, V., Scholz, C. C. et al. (2015). Fre- quently asked questions in hypoxia research. Hypoxia (Auckl) 3, 35-43. doi:10.2147/HP.S9219

WHO (2010). Recommendations for the evaluation of animal cell cultures as substrates for the manufacture of biological medicinal products and for the characterisation of cell banks. WHO Press, World Health Organization TRS878, Annex 1. https:// www.who.int/biologicals/Cell_Substrates_clean_version_ 18_April.pdf?ua=1

Wilkinson, M. D., Dumontier, M., Aalbersberg, I. J. et al. (2016). The FAIR guiding principles for scientific data management and stewardship. Sci Data 15, 160018. doi:10.1038/sdata. 2016.18. Erratum in: Sci Data 6, 6.

Wong, M. K., Li, E. W., Adam, M. et al. (2020). Establishment of an in vitro placental barrier model cultured under physiologically relevant oxygen levels. Mol Hum Reprod 26, 353-365. doi:10.1093/molehr/gaaa018

Xu, J., Du, Y. Y. and Deng, H. K. (2015). Direct lineage reprogramming: Strategies, mechanisms, and applications. Cell Stem Cell 16, 119-134. doi:10.1016/j.stem.2015.01.013

Zhang, D. H. and Jiang, W. (2015). From one-cell to tissue: Reprogramming, cell differentiation and tissue engineering. Bioscience 65, 468-475. doi:10.1093/biosci/biv016

Zeeberg, B., Riss, J., Kane, D. et al. (2004). Mistaken identifiers: Gene name errors can be introduced inadvertently when using Excel in bioinformatics. BMC Bioinformatics 5, 80. doi:10.1186/1471-2105-5-80

Zhang, Y., Zhang, H., Dong, X. et al. (2010). Hantavirus outbreak associated with laboratory rats in Yunnan, China. Infect Genet Evol 10, 638-644. doi:10.1016/j.meegid.2010.03.015

Ziemann, M., Eren, Y. and El-Osta, A. (2016). Gene name errors are widespread in the scientific literature. Genome Biol 17, 177. doi:10.1186/s13059-016-1044-7

\section{Acknowledgements}

Expert text editing by Mike Hughes, CAAT, is gratefully appreciated. We are grateful to all members of the Scientific Advisory Committee (Appendix $8^{1}$ ) who have provided useful comments and suggestions to the first draft and endorsed the final document. 